\title{
Progresses on the Use of Two-Photon Absorption Laser Induced Fluorescence (TALIF) Diagnostics for Measuring Absolute Atomic Densities in Plasmas and Flames
}

\author{
Kristaq Gazeli *(D), Guillaume Lombardi *, Xavier Aubert, Corinne Y. Duluard D, Swaminathan Prasanna \\ and Khaled Hassouni
}

Citation: Gazeli, K.; Lombardi, G.; Aubert, X.; Duluard, C.Y.; Prasanna, S.; Hassouni, K. Progresses on the Use of Two-Photon Absorption Laser Induced Fluorescence (TALIF) Diagnostics for Measuring Absolute Atomic Densities in Plasmas and Flames. Plasma 2021, 4, 145-171. https://doi.org/10.3390/ plasma4010009

Academic Editor:

Andrey Starikovskiy

Received: 10 January 2021

Accepted: 1 March 2021

Published: 4 March 2021

Publisher's Note: MDPI stays neutral with regard to jurisdictional claims in published maps and institutional affiliations.

Copyright: (c) 2021 by the authors. Licensee MDPI, Basel, Switzerland. This article is an open access article distributed under the terms and conditions of the Creative Commons Attribution (CC BY) license (https:// creativecommons.org/licenses/by/ $4.0 /)$
University Sorbonne Paris Nord, LSPM, CNRS, UPR 3407, F-93430 Villetaneuse, France; xavier.aubert@lspm.cnrs.fr (X.A.); Corinne.DULUARDCURLEY@1spm.cnrs.fr (C.Y.D.); Swaminathan.PRASANNA@lspm.cnrs.fr (S.P.); Khaled.HASSOUNI@lspm.cnrs.fr (K.H.)

* Correspondence: kristaq.gazeli@lspm.cnrs.fr (K.G.); GUILLAUME.LOMBARDI@lspm.cnrs.fr (G.L.)
Abstract: Recent developments in plasma science and technology have opened new areas of research both for fundamental purposes (e.g., description of key physical phenomena involved in laboratory plasmas) and novel applications (material synthesis, microelectronics, thin film deposition, biomedicine, environment, flow control, to name a few). With the increasing availability of advanced optical diagnostics (fast framing imaging, gas flow visualization, emission/absorption spectroscopy, etc.), a better understanding of the physicochemical processes taking place in different electrical discharges has been achieved. In this direction, the implementation of fast (ns) and ultrafast (ps and fs) lasers has been essential for the precise determination of the electron density and temperature, the axial and radial gradients of electric fields, the gas temperature, and the absolute density of ground-state reactive atoms and molecules in non-equilibrium plasmas. For those species, the use of laser-based spectroscopy has led to their in situ quantification with high temporal and spatial resolution, with excellent sensitivity. The present review is dedicated to the advances of two-photon absorption laser induced fluorescence (TALIF) techniques for the measurement of reactive species densities (particularly atoms such as $\mathrm{N}, \mathrm{H}$ and $\mathrm{O}$ ) in a wide range of pressures in plasmas and flames. The requirements for the appropriate implementation of TALIF techniques as well as their fundamental principles are presented based on representative published works. The limitations on the density determination imposed by different factors are also discussed. These may refer to the increasing pressure of the probed medium (leading to a significant collisional quenching of excited states), and other issues originating in the high instantaneous power density of the lasers used (such as photodissociation, amplified stimulated emission, and photoionization, resulting to the saturation of the optical transition of interest).

Keywords: ultrafast lasers; TALIF; fluorescence; absolute density; reactive species

\section{Introduction}

Following the construction of the first operating laser in 1960 by Theodore H. Maiman [1] based on a ruby crystal, a plethora of laser-based technological outcomes has emerged, and continues to be developed up to date.

The high energy density, the exceptional spatial and temporal resolution, and the selective production of monochromatic radiation over a wide wavelength range, have made lasers essential tools in industrial, medical, analytical, space-technology, and many other applications [2,3]. For instance, commercial lasers are widely used as multimode light sources in light shows for public entertainment. Additionally, they have been wellestablished in metallurgical industry for welding and cutting of different metals [4,5]. Their implementation in many other aspects of everyday life is also well-known, including laser projectors, printers, pointers, lithography, micromachining, medical lasers for aes- 
thetic purposes, surgery and dentistry, laser microscopy, elemental analysis of numerous materials/substances (including space exploration), and many other examples [6-11].

Furthermore, many research laboratories take advantage of the unique properties of lasers in order to conduct high-level fundamental and applied research. Typical examples refer to the following:

- Scattering techniques to measure electron density and temperature (Thomson scattering), and gas temperature (Rayleigh and Raman scattering) in plasmas [12,13];

- Tunable diode laser absorption spectroscopy (TDLAS) to infer metastable species absolute densities in different electrical discharges [14-17];

- Electric field induced second harmonic (EFISH) generation for accessing electric field dynamics in plasmas [18-20];

- Femtosecond laser electronic excitation tagging (FLEET), and particle image velocimetry (PIV) to infer gas dynamics in gas discharges [21,22];

- Laser induced fluorescence through the absorption of one (LIF) and two photons

(TALIF) for the determination of the absolute density of reactive molecules and atoms, respectively, in plasmas and flames [23-25].

The present review article is particularly devoted to the advances of TALIF spectroscopy for the study of reactive environments such as plasmas and flames. The manuscript is organized as follows. In Section 2, the basic theory of LIF/TALIF, and the experimental requirements for TALIF are introduced. Then, the paper focuses exclusively on the aspects of TALIF diagnostics. The reliable use of fast (ns) and ultrafast (ps/fs) lasers for the measurement of atomic species absolute densities in plasmas and flames is demonstrated in Section 3 (representative examples from the literature are discussed). Section 4 presents the major challenges encountered when using ns and ps/fs TALIF diagnostics. Finally, the principal conclusions are listed in Section 5.

\section{LIF and TALIF Spectroscopy}

\subsection{LIF Concept}

The concept of the laser induced fluorescence (LIF) technique, firstly introduced in the late 60 's by Tango et al. [26], is based on the absorption of laser radiation by species (atoms or molecules) that are generally found in their ground state, leading to their excitation to higher-energy levels. These are unstable and will decay spontaneously by emitting a photon. As so, fluorescence occurs due to the isotropic spontaneous emission of photons from those excited species through their relaxation to lower-energy levels. The density of species in the ground sate can be inferred from the recording/analysis of the emitted fluorescence. LIF is a diagnostic with excellent detection sensitivity; it allows for spatial and temporal measurements of the absolute density of ground-state species in different reactive media (e.g., plasmas and flames). Usually, excitation of ground-state molecules such as $\mathrm{OH}(X)$ and $\mathrm{NO}(X)$, is induced by one laser photon, the process being known as LIF [23-25,27]. The required photon energies in this case lie in the UV spectral range and can be achieved using commercial lasers. To determine the absolute density of a species of interest, LIF signals must be adequately calibrated against a well-known reference density. In the case of single-photon excitation (LIF), calibration of the spatial profile of the energy density of the laser and the properties of the optical detection system can be achieved by means of Rayleigh scattering (RS). This is usually performed in a noble gas of a known RS cross-section using the same system as in the LIF experiment [25,27-29]. Regarding TALIF, i.e., two-photon excitation, calibration with noble gases and titration methods are commonly used (see below).

The primary processes observed in a molecular system (e.g., $\mathrm{OH}, \mathrm{NO}, \mathrm{CO}$, etc.) when applying LIF are illustrated in Figure 1. The molecule being initially at a specific rovibrational level $\left(v^{\prime \prime}, J^{\prime \prime}\right)$ of its ground state $(G)$, absorbs a laser photon and reaches a different rovibrational level $(v /, J \prime)$ of an excited fluorescing electronic state $(E)$. The incident photon has an energy that is equal to the energy difference between levels $E(v /, J \prime)$ and $G\left(v^{\prime \prime}, J^{\prime \prime}\right)$. Following the species excitation, photon emission occurs from the relaxation 
of the excited state to an allowed lower level, as imposed by the quantum selection rules for electronic dipole transitions [30,31]. In Figure 1, different processes can be distinguished: (1) absorption of a single UV photon (red arrow) leads to molecular excitation from the ground state $G\left(v^{\prime \prime}, J^{\prime \prime}\right)$ to the higher-energy level $E(v /, J \prime)$, (2) stimulated emission (blue arrow), which is induced by the laser, leads to species de-excitation back to level $G\left(v^{\prime \prime}, J^{\prime \prime}\right)$; the loss of the density $(N)$ of the laser-excited state through spontaneous emission is given by $N \times A_{E G}$, where $A_{E G}$ is the Einstein coefficient of spontaneous emission for the transition between levels $E\left(v^{\prime}, J^{\prime}\right)$ and $G\left(v^{\prime \prime}, J^{\prime \prime}\right)$. This loss process and/or collisional quenching (depending on the pressure and species type) can be dominant at low laser intensities. However, when the laser intensity is significantly increased, the loss of the excited state through stimulated emission becomes significant. In fact, the loss of the excited-state density through stimulated emission is given by $N \times B_{E G} \times I$, where $B_{E G}$ is the Einstein coefficient for stimulated emission between the previous levels and $I$ is the laser intensity. Therefore, with increasing laser intensity the effect from stimulated emission increases as well, (3) quenching (black arrow) due to collisions with species of the same or different nature; it increases strongly with the medium's pressure, and induces a non-radiative de-population of the excited state, (4) pure fluorescence (green arrows) due to spontaneous emissions following the transition from the laser-excited state (or adjacent levels due to collisions, see below) to the ground state; it is essential for the determination of the species population density. On the above processes, one should also add possible collisional energy transfers. Due to these, the laser-excited state is excited/de-excited to adjacent energy levels, which are characterized by different rovibrational quantum numbers. It leads to emissions from excited states that were not directly populated by the laser. The above processes need to be taken into account when performing LIF experiments in order to deduce the pure fluorescence signal and achieve reliable density measurements. This can be achieved using adequate reaction-rate models based on molecular systems of a few energy levels $[25,32]$. In the following sections, similar processes will be discussed for TALIF diagnostics.

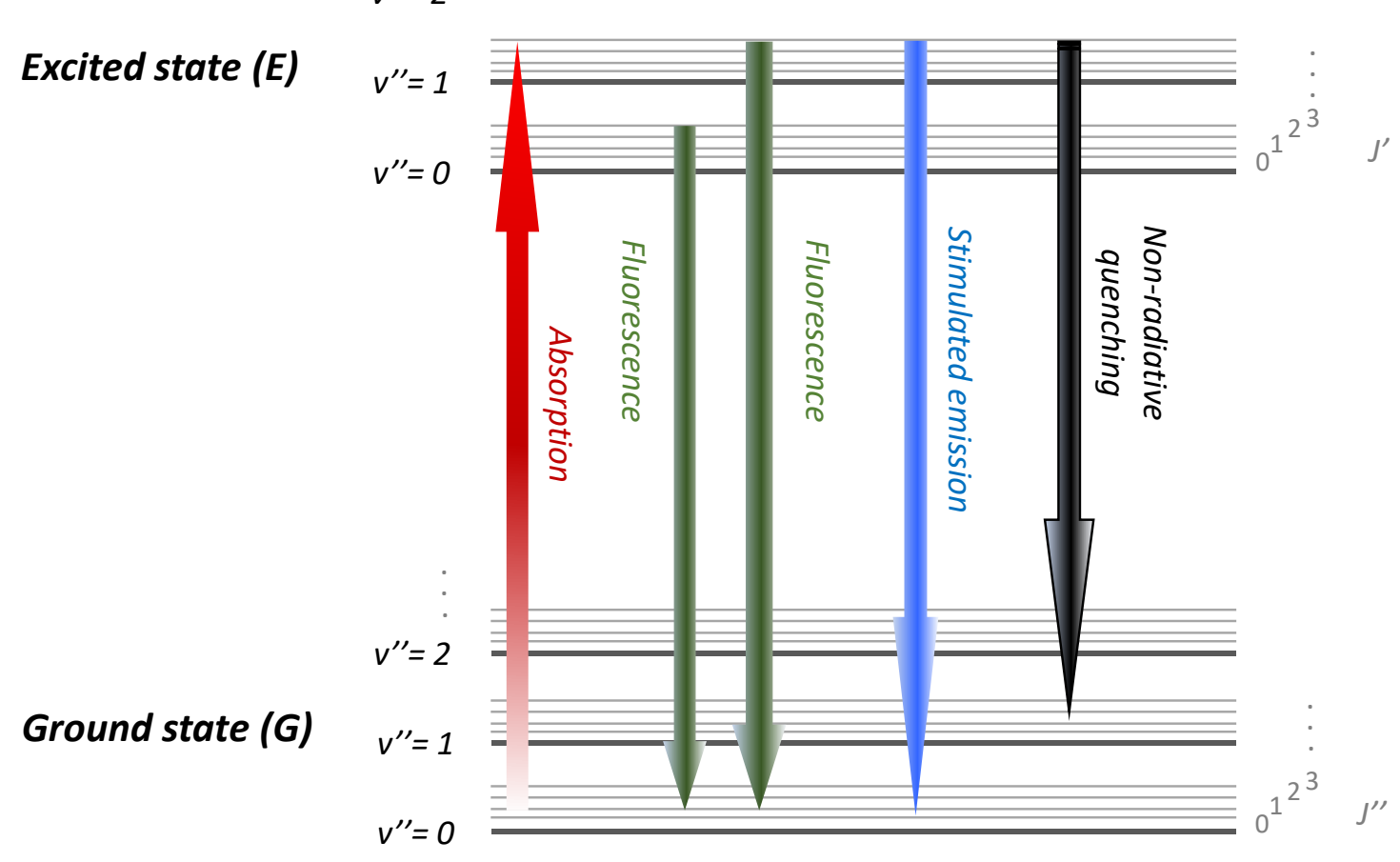

Figure 1. The primary processes observed in a molecular system when applying LIF. The system is composed from electronic $(G$ and $E)$, vibrational $\left(v^{\prime}\right.$ and $\left.v^{\prime \prime}\right)$, and rotational $\left(J^{\prime}\right.$ and $\left.J^{\prime \prime}\right)$ energy levels. 


\subsection{TALIF Principles, Involved Theory and Experimental Requirements}

In contrast to the case of LIF, for the excitation of atomic species, the required photon energies lie in the VUV spectral range, i.e., from 120 to $200 \mathrm{~nm}$. For experiments performed at atmospheric-pressure conditions, this makes the evaluation of atomic densities very difficult. This is due to the strong absorption of VUV photons by atmospheric species such as oxygen. To overcome this issue, excitation of atoms is achieved through a two-step absorption process using two UV laser photons, each one having half the energy of the initially required VUV photon. This method is known as TALIF, i.e., two-photon absorption LIF. Although TALIF is a very practical method, the two-photon absorption cross-sections are much smaller than single-photon absorption cross-sections (LIF). Consequently, greater instantaneous laser power densities are required. As a TALIF application example, the laser single-photon wavelengths (or energies) needed to excite atomic hydrogen $(\mathrm{H})$, nitrogen $(\mathrm{N})$, and oxygen $(\mathrm{O})$, to the $3 \mathrm{~d}^{2} \mathrm{D}_{3 / 2,5 / 2}, 3 \mathrm{p}{ }^{4} \mathrm{~S}_{3 / 2}$, and $3 \mathrm{p}^{3} \mathrm{P}_{1,2,0}$ excited fluorescing states, respectively, are of $102.5,103.3$, and $112.8 \mathrm{~nm}$, respectively. Thus, to probe those species, two-photon excitation has been applied, with the corresponding laser wavelengths (calculated in air) of each single photon being of 205.08, 206.6, and $225.6 \mathrm{~nm}$ [33-36]. Concerning the calibration of atomic density measurements performed with TALIF, the two-photon excitation is a non-linear process, making thus the RS method (linear process) not applicable. In this case, calibration is performed using titration techniques or reference noble gases (such as krypton-Kr and xenon-Xe), for which the absolute density is precisely known/controlled. More details on the calibration procedure are given further in the text.

The potential use of TALIF for probing reactive atoms such as $\mathrm{H}, \mathrm{N}$ and $\mathrm{O}$ has been demonstrated by some pioneering works in the $80^{\prime}$ s $[33,34,37,38]$. Since then, a plethora of experimental and numerical studies has emerged. These studies validated the excellent capability of TALIF to determine atomic densities in flames and plasmas [28,36,39-54]. The concept of this method is depicted in Figure 2. For a given atom, a simplified three-level TALIF scheme can be employed. This figure depicts the dominant physical processes taking place after the two-photon excitation (blue) of the ground-state atom to an excited fluorescing level E2. These are the following: (1) pure fluorescence (orange) due to the radiative relaxation from E2 to a lower-energy level E3; it is necessary for the evaluation of the atom's absolute density (see below), (2) photoionization (blue) from E2 by means of a third laser photon, (3) stimulated emission (brown) from E2 to E3, which results from a population inversion between E2 and E3, and (4) collisional quenching (grey) from E2 to other states such as the E3 and the ground state. The latter depends strongly on the pressure of the probed medium. This scheme is simpler than that of LIF shown in Figure 1 since rovibrational degrees of freedom are not associated with atomic species [31]. The above-mentioned processes will be discussed in more detail in the next sections.

It should be mentioned that the electronic transitions happening between the atomic energy levels in Figure 2 are governed by specific selection rules. These define the allowed and forbidden transitions between the different quantum levels of an atom taking into account the angular momentum and the parity of the related levels. More details can be found in $[30,31,55]$. For the simplified example of Figure 2, the kinetics of the population densities of the atom at its different energy states can be described using adequate rate equations. First, absorption of two laser photons is happening, which leads to the depletion of the density of the ground state $\left(N_{E 1}\right)$ and the population of the density of the excited state E2 $\left(N_{E 2}\right)$. The population and depopulation of states E1 and E2 can be described by Equations (1) and (2), as follows [36]:

$$
\begin{gathered}
\frac{d N_{E 1}}{d t}=-W_{E 1 \rightarrow E 2}(t) \times N_{E 1} \\
\frac{d N_{E 2}}{d t}=W_{E 1 \rightarrow E 2}(t) \times N_{E 1}-N_{E 2} \times \sum\left(A_{2}, Q_{2}, \Gamma_{2}, W_{E 2 \rightarrow E 3}(t)\right)
\end{gathered}
$$

where $W_{E 1 \rightarrow E 2}$ is the two-photon absorption rate from E1, and $W_{E 2 \rightarrow E 3}$ is the rate of stimulated emission from E2 to E3 [54]. The terms $A_{2}$ and $Q_{2}$ describe the density loss from 
E2 due to spontaneous emission at different lower levels $\mathrm{E} l\left(A_{2}=\sum_{l} A_{E 2 \rightarrow E l}\right.$, including the fluorescing channel $\mathrm{E} 2 \rightarrow \mathrm{E} 3$ ), and collisional quenching with different quenchers $q$ $\left(Q_{2}=\sum_{q} n_{q} k_{q}, k_{q}\right.$ being a reaction rate coefficient), respectively; $k_{q}$ values of common laser-excited atomic species such as $\operatorname{Kr}\left(5 \mathrm{p}^{\prime}[3 / 2]_{2}\right), \mathrm{H}\left(3 \mathrm{~d}^{2} \mathrm{D}_{\mathrm{J}}\right), \mathrm{N}\left(3 \mathrm{~s}^{4} \mathrm{P}_{3 / 2}\right), \mathrm{Xe}\left(7 \mathrm{p}[3 / 2]_{2}\right)$, and $\mathrm{O}\left(3 \mathrm{p}^{3} \mathrm{P}_{\mathrm{J}}\right)$ are given in [36] for different collision partners. The term $\Gamma_{2}$ in Equation (2) describes the E2 density loss due to photoionization by a third laser photon. When the depletion of E1 and E2 densities through laser excitation and photoionization/stimulated emission, respectively, is negligible, the atom will remain at E2 for a finite period of time $\tau_{\text {nat }}$. This is known as the natural lifetime of the excited state, it depends on the investigated species, and it is equal to $1 / A_{2}$. However, with increasing pressure of the probed medium, collisional quenching becomes significant depending on the excited species and the quencher nature [36]. Thus, the excited-state lifetime is decreased and its effective lifetime $\left(\tau_{e f f}\right)$ is now given by $\tau_{e f f}=1 /\left(A_{2}+Q_{2}\right)$.

The quantity $W_{E 1 \rightarrow E 2}$ is a function of the lineshape-independent two-photon absorption cross-section $\left(\sigma^{(2)}\right.$, units $\left.\mathrm{cm}^{4}\right)$, the spectral overlap $g(\delta v)$ factor between the atomic absorption line and the normalized laser emission line of central frequency $v$, the photon statistical factor $G^{(2)}$ (equals to 2 for the absorption of two photons from a chaotic multimode laser), and the ratio of the squared laser intensity $I(t)$ (units $W / \mathrm{cm}^{2}$ ) to the laser photon energy $h v$, as follows [36,55]:

$$
W_{E 1 \rightarrow E 2}(t)=\sigma^{(2)} g(v) G^{(2)}\left(\frac{I(t)}{h v}\right)^{2}
$$

The factor $G^{(2)}$ is related to the statistical properties of the intensity fluctuations in chaotic light such as in the case of pulsed (ns, ps, fs) multimode lasers used in TALIF experiments. For the absorption of two photons from a chaotic multimode laser, $G^{(2)}$ has a value of 2 [56]. In this case, to account for the effect on the TALIF signal of the laser intensity fluctuations, we cannot simply consider an averaged $I(t)$. Even if the laser temporal profile is measured shot by shot, fluctuations occurring in a timescale shorter than the response time of the measurement are averaged in the measurement of $\langle\mathrm{I}(\mathrm{t})\rangle$. By multiplying, thus, the absorption rate by $G^{(2)}$, we can avoid this issue. Considering a k-photon process and a Gaussian chaotic light, the value of $G^{(k)}$ is given by the following equation [57]:

$$
G^{(k)}=\left\langle\mathrm{I}^{\mathrm{k}}(\mathrm{t})\right\rangle /\langle\mathrm{I}(\mathrm{t})\rangle^{\mathrm{k}}=\mathrm{k} !
$$

where $I(t)$ is the actual laser pulse measured by an adequately fast detector (such as a streak camera, which is capable to capture all its time variations) and the brackets denote averaging over a large number of laser shots. It should be noted that when calibration with noble gases is applied, this parameter is cancelled out. For a detailed analysis of its calculation the reader is referred to references [56-60]. Integrating Equations (2) and (3) over a long time period, one gets the total number of photons emitted per unit volume, at the fluorescence frequency of the E2 $\rightarrow \mathrm{E} 3$ transition, as follows:

$$
N_{E 2 \rightarrow E 3}=\frac{A_{2 \rightarrow 3}}{A_{2}+Q_{2}} N_{E 1} \frac{\sigma^{(2)} g(\delta v) G^{(2)}}{(h v)^{2}} \int_{0}^{\infty} I^{2}(t) d t
$$

where $v$ is the laser central frequency, and the quantity $a_{2 \rightarrow 3}=\frac{A_{2 \rightarrow 3}}{A_{2}+Q_{2}}$ is the fluorescence yield. Then, the temporally-integrated fluorescence signal $S_{D}$, which can be recorded experimentally by means of a detector (e.g., photomultiplier tube, fast camera, etc.), is expressed as follows:

$$
S_{D}=\eta T V \frac{\Delta \Omega}{4 \pi} N_{E 2 \rightarrow E 3}
$$


$\eta$ being the detector's quantum efficiency, $T$ the transmission of the different optics used (e.g., interference filters, lenses, etc.), $V$ the collection volume and $\Delta \Omega$ the solid angle of collection of the fluorescence.

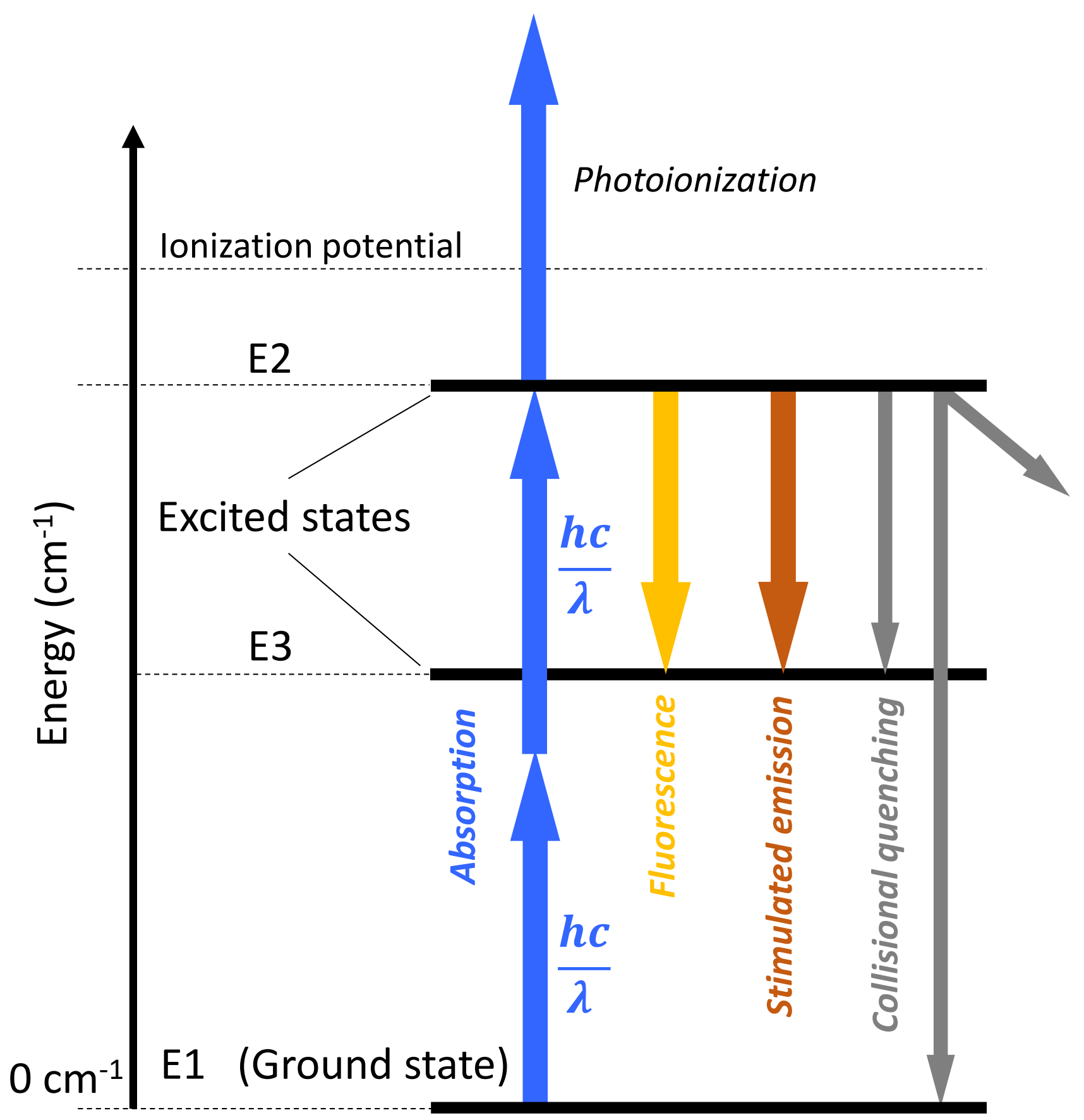

Figure 2. Generalized two-photon absorption (i.e., $2 \times h c / \lambda$, with $h, c$, and $\lambda$ being the Planck's constant, light speed, and laser excitation wavelength, respectively) and TALIF detection scheme for an atomic species.

Figure 3 depicts a simplified experimental setup that can be used to perform TALIF diagnostics, e.g., when studying an electric discharge (this holds for other reactive media as well such as flames). The discharge can be produced in different gases (e.g., $\mathrm{N}_{2}, \mathrm{O}_{2}$, $\mathrm{H}_{2}, \mathrm{He} / \mathrm{O}_{2} / \mathrm{N}_{2}, \mathrm{Ar} / \mathrm{N}_{2}$, etc.), and ignited over a large range of pressures (from low to atmospheric or even higher). Using adequate focusing lenses, the laser beam can be focused to the zone of TALIF collection, and then guided to an energy meter. The laser operates in pulsed mode (with ns, ps or fs pulse duration) at a typical repetition frequency of a few $\mathrm{Hz}$ 
(higher frequencies can also be available [45,61]). A selection of pulsed lasers used in the literature for probing very common reactive atoms $(\mathrm{H}, \mathrm{N}$, and $\mathrm{O})$ in gas discharges and flames is given in Tables 1 and 2 referring to ns- and ps/fs-TALIF, respectively. As already mentioned, a feature of the fluorescence is that it is emitted isotropically. The related transitions lie in the VIS-NIR spectral range (see Tables 1 and 2). Thus, it can be collected at various angles with respect to the laser beam. However, in most of the cases, TALIF is acquired at a $90^{\circ}$ angle, as shown in Figure 3, to achieve the optimal spatial resolution while filtering out the laser beam and stimulated emission spatially. The collection of fluorescence is achieved using another focusing lens and a narrow bandpass filter to filter out any stray light that can interfere with the TALIF signal. In many works, high-resolution spectrometers are preferred for the precise selection of the wavelength of interest [62]. The TALIF signal is then recorded with fast detectors mounted at the exit of the spectrometer. These must present time responses that are much shorter than the characteristic decay time of the fluorescing species in order to record the signal reliably. A representative example can be found in [61]. The authors measured by means of ns-TALIF the atomic oxygen density in a microwave plasma jet operating in a gas mixture of $\mathrm{He}$ and dry air at atmospheric pressure. The laser used had a pulse duration of a few ns and peak energy of $1-3 \mu \mathrm{J}$, and was operated at a repetition frequency of $1-2 \mathrm{kHz}$. TALIF was detected using a monochromator coupled with a photomultiplier tube, which was operated in the photon counting mode achieving a time resolution of $1 \mathrm{~ns}$. This resolution was sufficient to resolve temporally the TALIF decay.

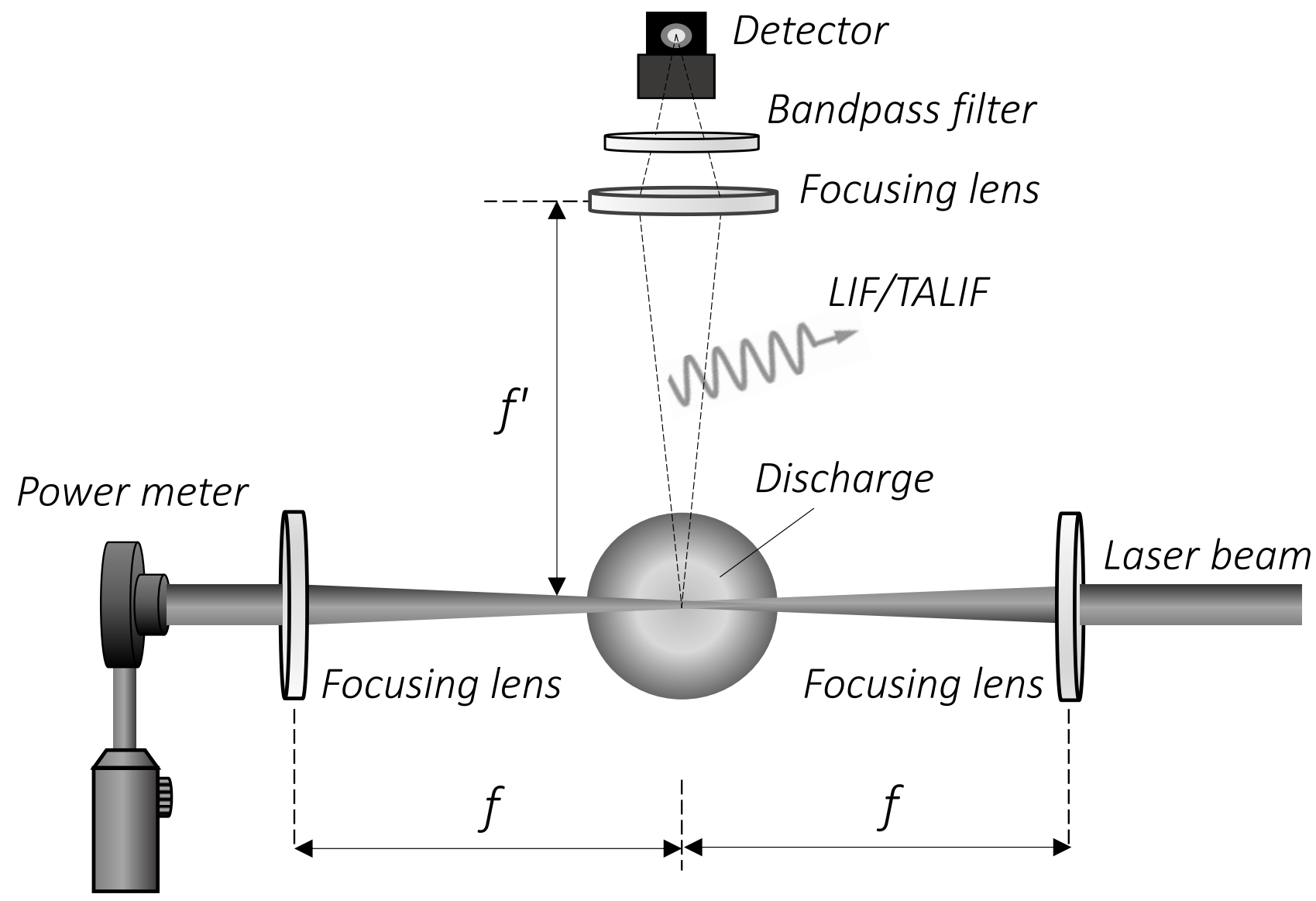

Figure 3. Simplified representation of an experimental arrangement typically used to perform TALIF diagnostics in a gas discharge. 
Table 1. Excitation schemes and laser characteristics used in different ns-TALIF studies to probe the most common atomic species $(\mathrm{H}, \mathrm{N}$ and $\mathrm{O})$ in plasmas and flames.

\begin{tabular}{|c|c|c|c|c|c|}
\hline Conditions & Pulse & Pulse & Species: & Laser/TALIF & Reference \\
\hline Laser Used & Duration/Energy & Frequency & Fluorescence Transition & & \\
\hline$A r F$ & $4-5 \mathrm{~ns} / 2 \mathrm{~mJ}$ & $10 \mathrm{~Hz}$ & $\mathrm{H}: \mathrm{n}=3 \rightarrow \mathrm{n}=2$ & $205 / 656.3$ & [33] \\
\hline Nd:YAG + Dye & $10 \mathrm{~ns} / 0.5 \mathrm{~mJ}$ & $20 \mathrm{~Hz}$ & $\mathrm{H}: \mathrm{n}=3 \rightarrow \mathrm{n}=2$ & $205 / 656.3$ & [63] \\
\hline$N d: Y A G+D y e$ & $-/ 50-60 \mu \mathrm{J}$ & - & $\mathrm{H}: 3 \mathrm{~d}^{2} \mathrm{D}_{3 / 2,5 / 2} \rightarrow 2 \mathrm{p}^{2} \mathrm{P}_{1 / 2,3 / 2}$ & $205.08 / 656.3$ & [64] \\
\hline Nd:YAG + Dye & $6 \mathrm{~ns} / 0.3-0.7 \mathrm{~mJ}$ & $10 \mathrm{~Hz}$ & $\mathrm{H}: 3 \mathrm{~d}^{2} \mathrm{D}_{3 / 2,5 / 2} \rightarrow 2 \mathrm{p}^{2} \mathrm{P}_{1 / 2,3 / 2}$ & $205 / 656.3$ & [65] \\
\hline Nd:YAG + Dye & $6 \mathrm{~ns} / 250 \mu \mathrm{J}$ & $10 \mathrm{~Hz}$ & $\mathrm{H}: 3 \mathrm{~d}^{2} \mathrm{D}_{3 / 2,5 / 2} \rightarrow 2 \mathrm{p}^{2} \mathrm{P}_{1 / 2,3 / 2}$ & $205.08 / 656$ & [42] \\
\hline$N d: Y A G+D y e$ & $-/ 4 \mathrm{~mJ}$ & - & $\mathrm{N}: 2 \mathrm{p}^{2} 3 \mathrm{p}^{4} \mathrm{D}^{0} \rightarrow 2 \mathrm{p}^{2} 3 \mathrm{~s}^{4} \mathrm{P}$ & $211 / 869$ & [48] \\
\hline$N d: Y A G+D y e$ & $-/ 150 \mu \mathrm{J}$ & - & $\mathrm{N}:(3 p)^{4} S_{3 / 2}^{0} \rightarrow(3 s)^{4} \mathrm{P}$ & $207 / \sim 745$ & [66] \\
\hline$N d: Y A G+D y e$ & $5 \mathrm{~ns} / 130 \mu \mathrm{J}$ & $20 \mathrm{~Hz}$ & $\mathrm{~N}:(3 \mathrm{p})^{4} \mathrm{~S}_{3 / 2} \rightarrow(3 \mathrm{~s})^{4} \mathrm{P}_{1 / 2,3 / 2,5 / 2}$ & $206.7 / 742-747$ & [67] \\
\hline$N d: Y A G+D y e$ & $5 \mathrm{~ns} / 1 \mathrm{~mJ}$ & $10 \mathrm{~Hz}$ & $\mathrm{~N}:(3 \mathrm{p})^{4} \mathrm{~S}_{3 / 2}^{0} \rightarrow(3 \mathrm{~s})^{4} \mathrm{P}_{1 / 2,3 / 2,5 / 2}$ & $206.65 / 742-746$ & [68] \\
\hline$N d: Y A G+D y e$ & $-/ 80-370 \mu \mathrm{J}$ & - & $\begin{array}{c}\mathrm{N}:(3 \mathrm{~s})^{4} \mathrm{D}_{7 / 2}^{0} \rightarrow(3 \mathrm{~s})^{4} \mathrm{P}_{5 / 2} \\
\mathrm{~N}:(3 \mathrm{p})^{4} \mathrm{~S}_{3 / 2}^{0} \rightarrow(3 \mathrm{~s})^{4} \mathrm{P}\end{array}$ & $\begin{array}{l}211 / 868 \\
207 / 745\end{array}$ & [69] \\
\hline$N d: Y A G+D y e$ & $10 \mathrm{~ns} / 5 \mathrm{~mJ}$ & $10 \mathrm{~Hz}$ & $\mathrm{~N}:(3 \mathrm{p})^{4} \mathrm{~S}_{3 / 2}^{0} \rightarrow(3 \mathrm{~s})^{4} \mathrm{P}_{1 / 2,3 / 2,5 / 2}$ & $206.72 / 742-746$ & [70] \\
\hline$N d: Y A G+D y e$ & $8 \mathrm{~ns} /-$ & - & $\mathrm{N}:(3 \mathrm{p})^{4} \mathrm{~S}_{3 / 2}^{0} \rightarrow(3 \mathrm{~s})^{4} \mathrm{P}_{1 / 2,3 / 2,5 / 2}$ & $206.65 / 744$ & [71] \\
\hline$N d: Y A G+D y e$ & $6.5 \mathrm{~ns} / 3 \mathrm{~mJ}$ & $10 \mathrm{~Hz}$ & $\mathrm{~N}:(3 \mathrm{p})^{4} \mathrm{~S}_{3 / 2}^{0} \rightarrow(3 \mathrm{~s})^{4} \mathrm{P}_{1 / 2,3 / 2,5 / 2}$ & $206.7 / 742-746$ & [72] \\
\hline$N d: Y A G+D y e$ & $5 \mathrm{~ns} / \leq 2.5 \mathrm{~mJ}$ & - & $\mathrm{O}: 3 \mathrm{p}^{3} \mathrm{P} \rightarrow 3 \mathrm{~s}^{3} \mathrm{~S}$ & $226 / 845$ & [73] \\
\hline Excimer + Dye & $-/ \sim 150 \mu \mathrm{J}$ & - & $\mathrm{O}: 3 \mathrm{p}^{5} \mathrm{P} \rightarrow 3 \mathrm{~s}^{5} \mathrm{~S}$ & $226 / 777$ & [74] \\
\hline$N d: Y A G+D y e$ & $5 \mathrm{~ns} / \leq 5.2 \mathrm{~mJ}$ & - & $\begin{array}{l}O: 3 p^{5} \mathrm{P} \rightarrow 3 s^{5} S \\
O: 3 p^{3} \mathrm{P} \rightarrow 3 s^{3} S\end{array}$ & $\begin{array}{l}226 / 777 \\
226 / 845\end{array}$ & [75] \\
\hline$N d: Y A G+D y e$ & $-/ \leq 185 \mu \mathrm{J}$ & - & $\mathrm{O}: 3 \mathrm{p}^{3} \mathrm{P} \rightarrow 3 \mathrm{~s}^{3} \mathrm{~s}$ & $226 / 845$ & [76] \\
\hline$N d: Y A G+D y e$ & $-/ \sim 350 \mu \mathrm{J}$ & - & $\mathrm{O}: 3 \mathrm{p}^{3} \mathrm{P}_{2} \rightarrow 3 \mathrm{~s}^{3} \mathrm{~S}_{1}$ & $225.582 / 844.6$ & [77] \\
\hline$N d: Y A G+D y e$ & $5 \mathrm{~ns} / 4 \mathrm{~mJ}$ & $10 \mathrm{~Hz}$ & $\mathrm{O}: 3 \mathrm{p}^{3} \mathrm{P}_{1,2,0} \rightarrow 3 \mathrm{~s}^{3} \mathrm{~S}$ & $225.65 / 844.87$ & [78] \\
\hline$N d: Y A G+D y e$ & $5 \mathrm{~ns} / 4 \mathrm{~mJ}$ & $10 \mathrm{~Hz}$ & $\mathrm{O}: 3 \mathrm{p}^{3} \mathrm{P}_{1,2,0} \rightarrow 3 \mathrm{~s}^{3} \mathrm{~S}$ & $225 / 844.87$ & [79] \\
\hline Nd:YAG + Dye & $5 \mathrm{~ns} / 4 \mathrm{~mJ}$ & $10 \mathrm{~Hz}$ & $\mathrm{O}: 3 \mathrm{p}^{3} \mathrm{P}_{1,2,0} \rightarrow 3 \mathrm{~s}^{3} \mathrm{~S}$ & $225.65 / 844.87$ & [80] \\
\hline$N d: Y A G+D y e$ & $-/ 1-3 \mu \mathrm{J}$ & $1-2 \mathrm{kHz}$ & $\mathrm{O}: 3 \mathrm{p}^{3} \mathrm{P}_{1,2,0} \rightarrow 3 \mathrm{~s}^{3} \mathrm{~S}$ & $225.586 / 844.68$ & [61] \\
\hline$N d: Y A G+D y e$ & $-/>0.1 \mathrm{~mJ}$ & - & $\mathrm{O}: 3 \mathrm{p}^{3} \mathrm{P}_{1,2,0} \rightarrow 3 \mathrm{~s}^{3} \mathrm{~S}$ & $226 / 844.68$ & [81] \\
\hline$N d: Y A G+D y e$ & $-/ 1-200 \mu \mathrm{J}$ & $10 \mathrm{~Hz}$ & $\mathrm{O}: 3 \mathrm{p}^{3} \mathrm{P}_{1,2,0} \rightarrow 3 \mathrm{~s}^{3} \mathrm{~S}_{1}$ & $225.58 / 844.6$ & [82] \\
\hline $\begin{array}{l}\text { Tuneable diode } \\
\text { Nd:YAG + Dye }\end{array}$ & $\begin{array}{c}-/- \\
-/ 250 \mu \mathrm{J}\end{array}$ & $\begin{array}{l}30 \mathrm{MHz} \\
20 \mathrm{~Hz}\end{array}$ & $\mathrm{O}: 3 \mathrm{p}^{3} \mathrm{P}_{1,2,0} \rightarrow 3 \mathrm{~s}^{3} \mathrm{~S}_{1}$ & $225.6 / 844.6$ & [83] \\
\hline$N d: Y A G+D y e$ & $5 \mathrm{~ns} / 0.3-0.5 \mathrm{~mJ}$ & $10 \mathrm{~Hz}$ & $\mathrm{O}: 3 \mathrm{p}^{3} \mathrm{P}_{1,2,0} \rightarrow 3 \mathrm{~s}^{3} \mathrm{~S}_{1}$ & $225.58 / 844.6$ & [84] \\
\hline$N d: Y A G+D y e$ & $20 \mathrm{~ns} /<0.4 \mathrm{~mJ}$ & - & $\mathrm{O}: 3 \mathrm{p}^{3} \mathrm{P} \rightarrow 3 \mathrm{~s}^{3} \mathrm{~S}$ & $225.6 / 844.6$ & [85] \\
\hline$N d: Y A G$ & $7 \mathrm{~ns} / 50-100 \mu \mathrm{J}$ & - & $\begin{array}{c}\text { O: } 3 p^{3} \mathrm{P} \rightarrow 3 s^{3} S \\
\mathrm{~N}: 2 \mathrm{p}^{2} 3 \mathrm{p}^{4} \mathrm{D}^{0} \rightarrow 2 \mathrm{p}^{2} 3 \mathrm{~s}^{4} \mathrm{P}\end{array}$ & $\begin{array}{l}226 / 845 \\
211 / 869\end{array}$ & [35] \\
\hline$N d: Y A G+D y e$ & $7 \mathrm{~ns} / 3 \mathrm{~mJ}$ & - & $\begin{array}{c}\mathrm{O}: 3 \mathrm{p}^{3} \mathrm{P} \rightarrow 3 \mathrm{~s}^{3} \mathrm{~S} \\
\mathrm{H}_{\alpha}: \mathrm{n}=3 \rightarrow \mathrm{n}=2\end{array}$ & $\begin{array}{c}226 / 845 \\
205 / 656.3\end{array}$ & [86] \\
\hline$N d: Y A G+D y e$ & $8 \mathrm{~ns} / 0.5 \mathrm{~mJ}$ & $10 \mathrm{~Hz}$ & $\begin{array}{c}\mathrm{H}: 3 \mathrm{~d}^{2} \mathrm{D}_{3 / 2,5 / 2} \rightarrow 2 \mathrm{p}^{2} \mathrm{P}_{1 / 2,3 / 2} \\
\mathrm{~N}:(3 \mathrm{p})^{4} \mathrm{~S}_{3 / 2}^{0} \rightarrow(3 \mathrm{~s})^{4} \mathrm{P}_{1 / 2,3 / 2,5 / 2} \\
\mathrm{O}: 3 \mathrm{p}^{3} \mathrm{P}_{1,2,0} \rightarrow 3 \mathrm{~s}^{3} \mathrm{~S}\end{array}$ & $\begin{array}{c}205.08 / 656.3 \\
206.65 / 742-746 \\
225.58 / 844.64\end{array}$ & [36] \\
\hline$N d: Y A G+D y e$ & $-/ 200 \mu \mathrm{J}$ & - & $\begin{array}{c}\mathrm{N}:(3 \mathrm{~s})^{4} \mathrm{D}_{7 / 2}^{0} \rightarrow(3 \mathrm{~s})^{4} \mathrm{P}_{5 / 2} \\
\mathrm{~N}:(3 \mathrm{p})^{4} \mathrm{~S}_{3 / 2}^{0} \rightarrow(3 \mathrm{~s})^{4} \mathrm{P} \\
\mathrm{O}: 3 \mathrm{p}^{3} \mathrm{P}_{2} \rightarrow 3 \mathrm{~s}^{3} \mathrm{~S}_{1}\end{array}$ & $\begin{array}{c}210.788 / 868.027 \\
206.718 / 746.83 \\
225.582 / 844.6\end{array}$ & [87] \\
\hline
\end{tabular}


Table 2. Excitation schemes and laser characteristics used in different ps- and fs-TALIF studies to probe the most common atomic species ( $\mathrm{H}, \mathrm{N}$ and $\mathrm{O})$ in plasmas and flames.

\begin{tabular}{|c|c|c|c|c|c|}
\hline $\begin{array}{l}\text { Conditions } \\
\text { Laser Used }\end{array}$ & $\begin{array}{c}\text { Pulse } \\
\text { Duration/Energy }\end{array}$ & $\begin{array}{c}\text { Pulse } \\
\text { Frequency }\end{array}$ & $\begin{array}{l}\text { Species: } \\
\text { Fluorescence Transition }\end{array}$ & $\begin{array}{c}\text { Laser/TALIF } \\
\text { Wavelength }(\mathrm{nm})\end{array}$ & Reference \\
\hline Nd:YAG+ Dye & $10 \mathrm{ps} / 20 \mu \mathrm{J}$ & $10 \mathrm{~Hz}$ & $\mathrm{H}: \mathrm{n}=3 \rightarrow \mathrm{n}=2$ & $205 / 656.3$ & [48] \\
\hline Nd:YAG+ Dye & $70 \mathrm{ps} / 0.3 \mathrm{~mJ}$ & $20 \mathrm{~Hz}$ & $\mathrm{H}: \mathrm{n}=3 \rightarrow \mathrm{n}=2$ & $205 / 656.3$ & [88] \\
\hline$N d: Y A G+D y e$ & $100 \mathrm{ps} / 0.4 \mathrm{~mJ}$ & $20 \mathrm{~Hz}$ & $\mathrm{H}: \mathrm{n}=3 \rightarrow \mathrm{n}=2$ & $205.144 / 656.3$ & [53] \\
\hline $\begin{array}{c}\text { Nd:YLF } \\
\text { Ti: Sapphire }\end{array}$ & $100 \mathrm{fs} / 62 \mathrm{~mW}$ & $1 \mathrm{kHz}$ & $\mathrm{N}:(3 p)^{4} S_{3 / 2}^{0} \rightarrow(3 s)^{4} P_{1 / 2,3 / 2,5 / 2}$ & $206.65 / 742-746$ & [62] \\
\hline Nd:YAG+ Dye & $10 \mathrm{ps} / 40 \pm 20 \mu \mathrm{J}$ & $10 \mathrm{~Hz}$ & $\mathrm{O}: 3 \mathrm{p}^{3} \mathrm{P} \rightarrow 3 \mathrm{~s}^{3} \mathrm{~S}$ & $226 / 845$ & [47] \\
\hline$N d: Y A G+D y e$ & $55 \mathrm{ps} / 3 \mu \mathrm{J}$ & $20 \mathrm{~Hz}$ & $\mathrm{O}: 3 \mathrm{p}^{3} \mathrm{P} \rightarrow 3 \mathrm{~s}^{3} \mathrm{~s}$ & $225.655 / 845$ & [89] \\
\hline$N d: Y A G+D y e$ & $55 \mathrm{ps} / 2-1200 \mu \mathrm{J}$ & $20 \mathrm{~Hz}$ & $\mathrm{O}: 3 \mathrm{p}^{3} \mathrm{P} \rightarrow 3 \mathrm{~s}^{3} \mathrm{~S}$ & $225.655 / 845$ & {$[52]$} \\
\hline$N d: Y A G+D y e$ & $100 \mathrm{ps} / 600 \mu \mathrm{J}$ & - & $\mathrm{O}: 3 \mathrm{p}^{3} \mathrm{P} \rightarrow 3 \mathrm{~s}^{3} \mathrm{~S}$ & $225.655 / 845$ & [51] \\
\hline Ti: Sapphire & $100 \mathrm{fs} / 13 \mu \mathrm{J}$ & $1 \mathrm{kHz}$ & $\mathrm{O}: 3 \mathrm{p}^{3} \mathrm{P}_{1,2,0} \rightarrow 3 \mathrm{~s}^{3} \mathrm{~S}$ & $225.65 / 844.87$ & [45] \\
\hline Ti: Sapphire & $100 \mathrm{fs} / 12 \mu \mathrm{J}$ & $1 \mathrm{kHz}$ & $\mathrm{O}: 3 \mathrm{p}^{3} \mathrm{P}_{1,2,0} \rightarrow 3 \mathrm{~s}^{3} \mathrm{~S}$ & $225.59 / 844.65$ & [90] \\
\hline$N d: Y A G$ & $\begin{array}{l}30 \mathrm{ps} / 35 \mu \mathrm{J} \\
30 \mathrm{ps} / 24 \mu \mathrm{J}\end{array}$ & $10 \mathrm{~Hz}$ & $\begin{array}{c}\mathrm{H}_{\alpha}: \mathrm{n}=3 \rightarrow \mathrm{n}=2 \\
\mathrm{O}: 3 \mathrm{p}^{3} \mathrm{P}_{1,2,0} \rightarrow 3 \mathrm{~s}^{3} \mathrm{~S}_{1}\end{array}$ & $\begin{array}{l}205.08 / 656.3 \\
225.65 / 844.6\end{array}$ & {$[44]$} \\
\hline Ti: Sapphire & $\begin{array}{l}100 \mathrm{fs} / 10 \mu \mathrm{J} \\
100 \mathrm{fs} / 15 \mu \mathrm{J}\end{array}$ & $\begin{array}{l}10 \mathrm{kHz} \\
1 \mathrm{kHz}\end{array}$ & $\begin{array}{l}\mathrm{H}_{\alpha}: \mathrm{n}=3 \rightarrow \mathrm{n}=2 \\
\mathrm{O}: 3 \mathrm{p}^{3} \mathrm{P}_{1,2,0} \rightarrow 3 \mathrm{~s}^{3} \mathrm{~S}\end{array}$ & $\begin{array}{l}205.08 / 656.27 \\
225.59 / 844.65\end{array}$ & [91] \\
\hline
\end{tabular}

The evaluation of Equation (5) and, thus, the direct determination of species absolute densities with TALIF is challenging. This is because the measurement of the two-photon absorption cross-sections of different atoms is difficult due to their very low values. Besides, the solid angle and volume of collection of the fluorescence cannot be measured with an acceptable accuracy. To overcome geometrical issues, an adequate calibration method has been firstly introduced in reference [92], and has been widely employed in the literature to perform atomic density measurements with TALIF (see Tables 1 and 2). It is based on the TALIF application in noble gases of well-known absolute densities. These are not reactive and are chosen so that the laser excitation wavelengths are very close to those of the species of interest. For instance, for the calibration of the density measurements of $\mathrm{H} / \mathrm{N}$ and $\mathrm{O}$ atoms, TALIF is usually applied to krypton $(\mathrm{Kr})$ and xenon $(\mathrm{Xe})$ gases, respectively. Typical corresponding TALIF schemes are shown in Figure 4.

Figure 4 illustrates the UV laser wavelengths needed for two-photon excitation of $\mathrm{H}, \mathrm{N}, \mathrm{O}, \mathrm{Kr}$ and $\mathrm{Xe}$ from their ground to different excited fluorescing states. The corresponding fluorescence wavelengths are also shown. Based on these schemes and Equations (4) and (5), the absolute density of a species of interest $\left(N_{X}\right)$ is obtained, knowing the absolute density of the calibrating species $\left(N_{C}\right)$, as follows:

$$
N_{X}=N_{C} \frac{(\eta T)_{C}}{(\eta T)_{X}} \frac{a_{2 \rightarrow 3 C}}{a_{2 \rightarrow 3 X}} \frac{\left(\int_{0}^{\infty} I^{2}(t) d t\right)_{C}}{\left(\int_{0}^{\infty} I^{2}(t) d t\right)_{X}} \frac{v_{0 X}^{2}}{v_{0 C}^{2}} \frac{\sigma_{C}^{(2)}}{\sigma_{X}^{(2)}} \frac{g(\delta v)_{C}}{g(\delta v)_{X}} \frac{S_{D X}}{S_{D C}}
$$

In Equation (6), $\int_{0}^{\infty} I^{2}(t) d t$ is proportional to $E_{\text {Laser }}^{2}, E_{\text {Laser }}$ being the laser pulse energy

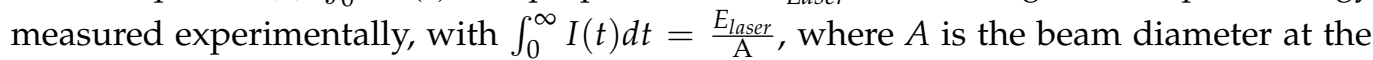
measurement position. Thus, when the space-time features of the laser beam are identical for species $X$ and $C$, the time integral in Equation (6) can be replaced by $E_{\text {Laser }}^{2}[36,45]$. Besides, $V, \frac{\Delta \Omega}{4 \pi}$ and $G^{(2)}$ are the same for both species and they are canceled out. The values of $\eta$ and $T$ corresponding to each species are obtained from the response at the wavelength of interest of the optics and the detector used. Furthermore, $v_{0}$ is the laser central frequency (or wavelength) used to induce the two-photon excitation, and $g\left(v_{0}\right)$ is the peak of the two-photon absorption line profile. For instance, in the case of a Gaussian 
profile, $g\left(v_{0}\right)$ is equal to $0.94 / F W H M$ [55]. Finally, $S_{D X}$ and $S_{D C}$ are the fluorescence signals that are measured experimentally, e.g., with a PMT. Thus, the only quantity that needs to be determined in Equation (6) is the ratio between the two-photon absorption cross-sections of the two concerned species $\left(\sigma_{C}^{(2)} / \sigma_{X}^{(2)}\right)$. Yet, these are not available for $\mathrm{Kr}$ and $\mathrm{Xe}$ in the literature. However, using titration methods, it was possible to directly infer different ratios which are given in Table 3 (typical natural lifetimes and quenching coefficients from common quenchers such as $\mathrm{N}_{2}$ and $\mathrm{O}_{2}$ are also given for the involved species).
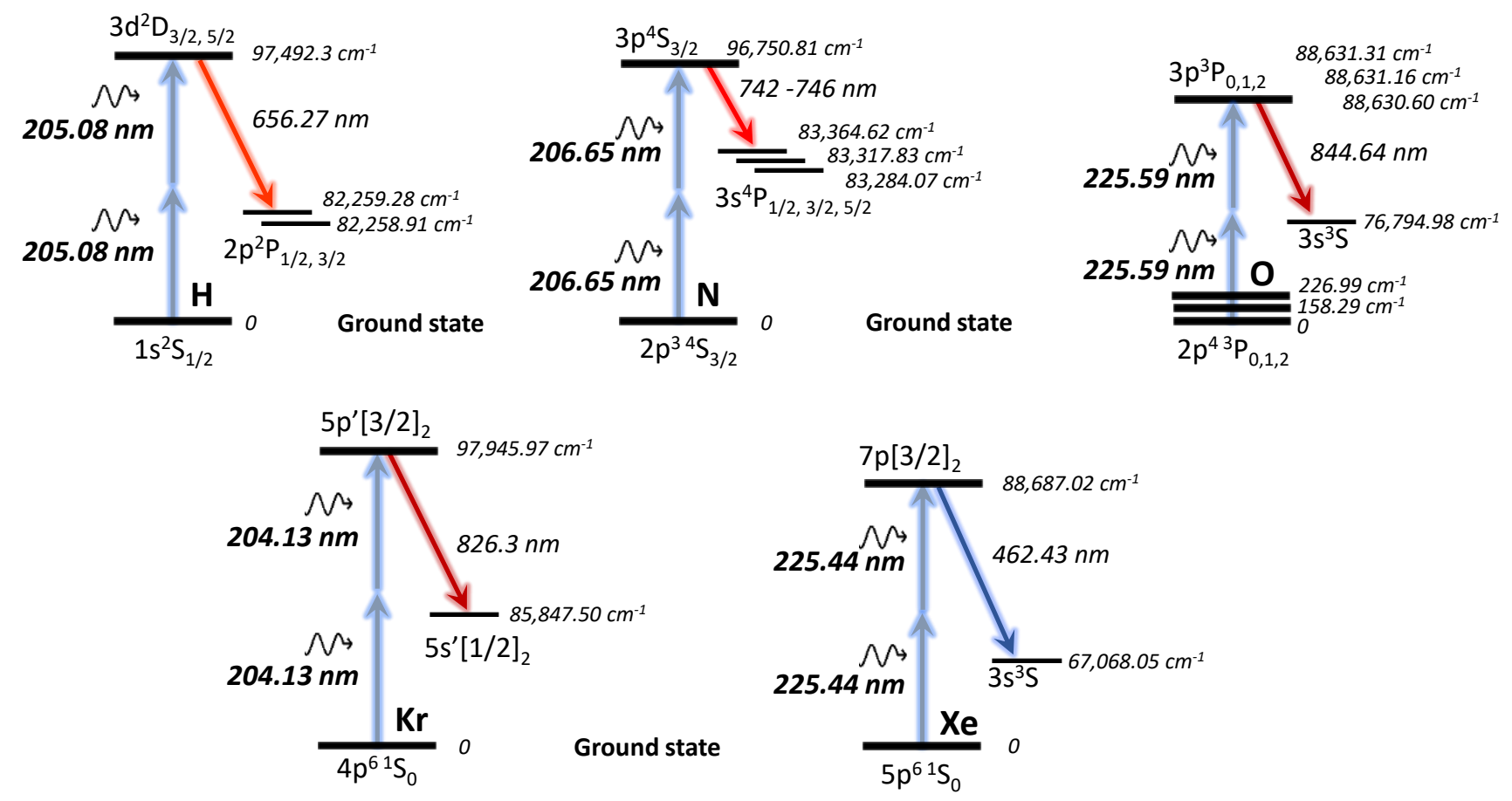

Figure 4. Upper figure. Two-photon excitation schemes for atomic hydrogen $(\mathrm{H})$, nitrogen (N), and oxygen (O). Lower figure. Two photon excitation schemes of noble gases: krypton (used for $\mathrm{H}$ - and $\mathrm{N}$-atom density calibration) and xenon (used for O-atom density calibration).

Table 3. Relative cross-section values, typical natural lifetimes, and quenching coefficients (two common quenchers, $\mathrm{N}_{2}$ and $\mathrm{O}_{2}$, are given; for more species see references [34,78]) for reactive $(\mathrm{H}, \mathrm{N}, \mathrm{O})$ and calibrating $(\mathrm{Kr}, \mathrm{Xe})$ atomic species commonly used in TALIF diagnostics.

\begin{tabular}{|c|c|c|c|c|}
\hline Quantities & \multirow{2}{*}{$\sigma^{(2)}$ (Relative) } & \multirow{2}{*}{$\tau_{\text {nat }}(\mathrm{ns})$} & \multicolumn{2}{|c|}{$\mathbf{k}_{\mathbf{q}}\left(10^{-10} \mathrm{~cm}^{3} \mathbf{s}^{-1}\right)$} \\
\hline Atom-Excited State & & & $\mathbf{N}_{2}$ & $\mathrm{O}_{2}$ \\
\hline $\mathrm{N}:(3 p)^{4} \mathrm{~S}_{3 / 2}^{0}$ & $\frac{\sigma_{K r}^{(2)}}{\sigma_{N}^{(2)}}=0.67 \pm 50 \%[36]$ & $29.6[36]$ & $0.41[36]$ & $6.63[36]$ \\
\hline $\mathrm{H}: 3 \mathrm{~d}^{2} \mathrm{D}_{3 / 2,5 / 2}$ & $\frac{\sigma_{K r}^{(2)}}{\sigma_{H}^{(2)}}=0.62 \pm 50 \%[36]$ & $17.6[36]$ & $20.1[36]$ & $32.6[36]$ \\
\hline $\mathrm{O}: 3 \mathrm{p}^{3} \mathrm{P}_{1,2,0}$ & $\begin{array}{l}\frac{\sigma_{X e}^{(2)}}{\sigma_{O}^{(2)}}=0.36 \pm 50 \%[36] \\
\frac{\sigma_{X e}^{(2)}}{\sigma_{O}^{(2)}}=0.51 \pm 50 \%[92] \\
\quad\left(\text { for Xe: } 7 p[3 / 2]_{2}\right) \\
\frac{\sigma_{X e}^{(2)}}{\sigma_{O}^{(2)}}=1.9( \pm 20 \%)[78] \\
\quad\left(\text { for Xe: } 6 p^{\prime}[3 / 2]_{2}\right)\end{array}$ & $\begin{array}{c}35.1[36] \\
34.7 \pm 1.7[78]\end{array}$ & $5.9[36]$ & $9.3[36]$ \\
\hline
\end{tabular}


Table 3. Cont.

\begin{tabular}{|c|c|c|c|c|}
\hline \multirow{2}{*}{$\begin{array}{c}\text { Quantities } \\
\text { Atom-Excited State }\end{array}$} & \multirow{2}{*}{$\sigma^{(2)}$ (Relative) } & \multirow{2}{*}{$\tau_{\text {nat }}(\mathrm{ns})$} & \multicolumn{2}{|c|}{$\mathbf{k}_{\mathbf{q}}\left(10^{-10} \mathbf{c m}^{3} \mathbf{s}^{-1}\right)$} \\
\hline & & & $\mathbf{N}_{2}$ & $\mathrm{O}_{2}$ \\
\hline $\mathrm{Kr}: 5 p^{\prime}[3 / 2]_{2}$ & $\begin{array}{l}\frac{\sigma_{K r}^{(2)}}{\sigma_{N}^{(2)}}=0.67 \pm 50 \%[36] \\
\frac{\sigma_{K r}^{(2)}}{\sigma_{H}^{(2)}}=0.62 \pm 50 \%[36]\end{array}$ & $34.1[36]$ & $3.35[36]$ & $6.64[36]$ \\
\hline Xe: $7 \mathrm{p}[3 / 2]_{2}$ & $\begin{array}{l}\frac{\sigma_{X e}^{(2)}}{\sigma_{O}^{(2)}}=0.36 \pm 50 \%[36] \\
\frac{\sigma_{X e}^{(2)}}{\sigma_{O}^{(2)}}=0.51 \pm 50 \%[92]\end{array}$ & $105.6[36]$ & $14[36]$ & $20.6[36]$ \\
\hline Xe: $6 p^{\prime}[3 / 2]_{2}$ & $\frac{\sigma_{X e}^{(2)}}{\sigma_{O}^{(2)}}=1.9( \pm 20 \%)[78]$ & $40.8 \pm 2[78]$ & & $9.4 \pm 0.5[36]$ \\
\hline
\end{tabular}

For $\mathrm{H}, \mathrm{N}$ and $\mathrm{O}$, corresponding theoretical and/or experimental values of $\sigma^{(2)}$ have been given in $[35,59,93-96]$. These depend on the species nature, the gas pressure, and the laser spectral characteristics. In different published works (e.g., in $[35,93,95]$ ), the two-photon absorption cross-sections can be found in the following units:

- $\quad \mathrm{cm}^{4}$, which is the atomic lineshape-independent cross-section $\left(\sigma^{(2)}\right)$ depending only on the nature of the atom;

- $\quad \mathrm{cm}^{4} \cdot \mathrm{s}$, resulting from the product: $\sigma^{(2)} g(\delta v) G^{(2)}$;

- $\quad \mathrm{cm}^{4} \cdot \mathrm{W}^{-1}$, resulting from the product: $2 \pi \sigma^{(2)} \mathrm{g}(\delta v) G^{(2)} / \mathrm{h} v, v$ being the laser photon frequency.

As an example, in the case of atomic oxygen the two-photon absorption cross-sections for the $2 p^{3} \mathrm{P}_{2} \rightarrow 3 \mathrm{p}^{3} \mathrm{P}_{2,1,0}$ transition have been measured experimentally in [59]. They were found to be of $2.66 \times 10^{-35} \mathrm{~cm}^{4}, 4.85 \times 10^{-46} \mathrm{~cm}^{4} \cdot \mathrm{s}$, and $5.5 \times 10^{-28} \mathrm{~cm}^{4} \cdot \mathrm{W}^{-1}$, respectively. The authors compared them with different corresponding theoretical values revealing a relatively good agreement between theory and experiment (see Table IV in [59]).

Another necessity when performing absolute density measurements of atomic species is the selection of appropriate laser energies, for which the consideration of Equations (5) and (6) is valid. This happens only when the measured TALIF signal intensity $\left(S_{D}\right)$ is proportional to the squared laser energy $\left(E_{\text {Laser }}^{2}\right)$. This condition is known as the quadratic regime of excitation, and is achieved when the following two requirements are fulfilled [55]:

1. The depletion by the laser radiation of the species ground-state by two-photon absorption is negligible. This is true when the corresponding inverse of the two-photon absorption rate (i.e., $1 / W_{E 1 \rightarrow E 2}(t)$, units in sec) is much higher than the duration of the laser pulse.

2. The depletion by photoionization (PIN) and amplified stimulated emission (ASE) of the laser-excited state is significantly lower than that due to spontaneous emission $(A)$ and collisional quenching $(Q)$. The implication of those processes in the TALIF scheme will be discussed in more detail in the next section.

Therefore, for reliable TALIF experiments, the quadratic regime must be guaranteed for both the calibrating and the reactive species of interest. This can be easily verified experimentally, by determining $S_{D}$ at various laser energies, and then plotting it as a function of $E_{\text {Laser }}$, as shown in Figure 5 (results obtained by our group when applying psTALIF in $\mathrm{Kr}$ at 4 mbar, also see reference [97] for different pressures and detailed analysis). In [45], fs-TALIF was performed in an atmospheric-pressure $\mathrm{He}-\mathrm{O}_{2}$ plasma jet to determine the absolute density of $\mathrm{O}$ atoms produced in the plasma. The $\mathrm{O}$-atom density calibration was performed using $\mathrm{Xe}$ gas. For $\mathrm{O}$ and $\mathrm{Xe}$ atoms, the quadratic regime was obtained for $E_{\text {Laser }}$ lower than 20 and $8 \mu \mathrm{J} /$ pulse, respectively. Thus, the authors chose to perform TALIF experiments at $E_{\text {Laser }}=13$ and $5.5 \mu \mathrm{J} /$ pulse, respectively, to achieve reliable density 
measurements. It should be noted that, for obtaining the quadratic regime, they constructed a laser sheet, thus keeping the average laser intensity as low as $6.7 \mathrm{~W} / \mathrm{cm}^{2}$ (i.e., similar to that of a ns-TALIF system used in the same studies [91]), while maintaining a peak intensity of $\sim 6.7 \times 10^{10} \mathrm{~W} / \mathrm{cm}^{2}$ being much higher than that of ns-TALIF $\left(8 \times 10^{7} \mathrm{~W} / \mathrm{cm}^{2}\right)$. Another noteworthy point is that, for strongly focused beams, the use of a similar fs-TALIF system in $\mathrm{N}$ and $\mathrm{Kr}$ atoms resulted to laser peak intensities as high as $\sim 4 \mathrm{TW} / \mathrm{cm}^{2}$, thus leading to saturation phenomena not allowing for the quadratic regime to be obtained [62]. In another work [65], the absolute density of $\mathrm{H}$ atoms in a ns-pulsed Ar plasma jet was evaluated by means of ns-TALIF. The H-atom density measurements were calibrated by means of ns-TALIF in Kr atoms. The quadratic regime was obtained for both atoms. Finally, using nsTALIF in the afterglow of a ns-pulsed discharge produced in $\mathrm{N}_{2}$ at $27 \mathrm{mbar}$, Chng et al. [72] determined the absolute density of $\mathrm{N}$ atoms. The $\mathrm{N}$-atom density calibration was achieved using $\mathrm{Kr}$ gas. For both species, the evolution of the TALIF signal intensity versus the laser intensity was plotted in log scales. The resulting graphs yielded slopes of $\sim 2$, confirming the quadratic regime for $E_{\text {Laser }}=85 \mu \mathrm{J} /$ pulse $(\mathrm{N}$ atom) and $30 \mu \mathrm{J} / \mathrm{pulse}(\mathrm{Kr}$ atom).

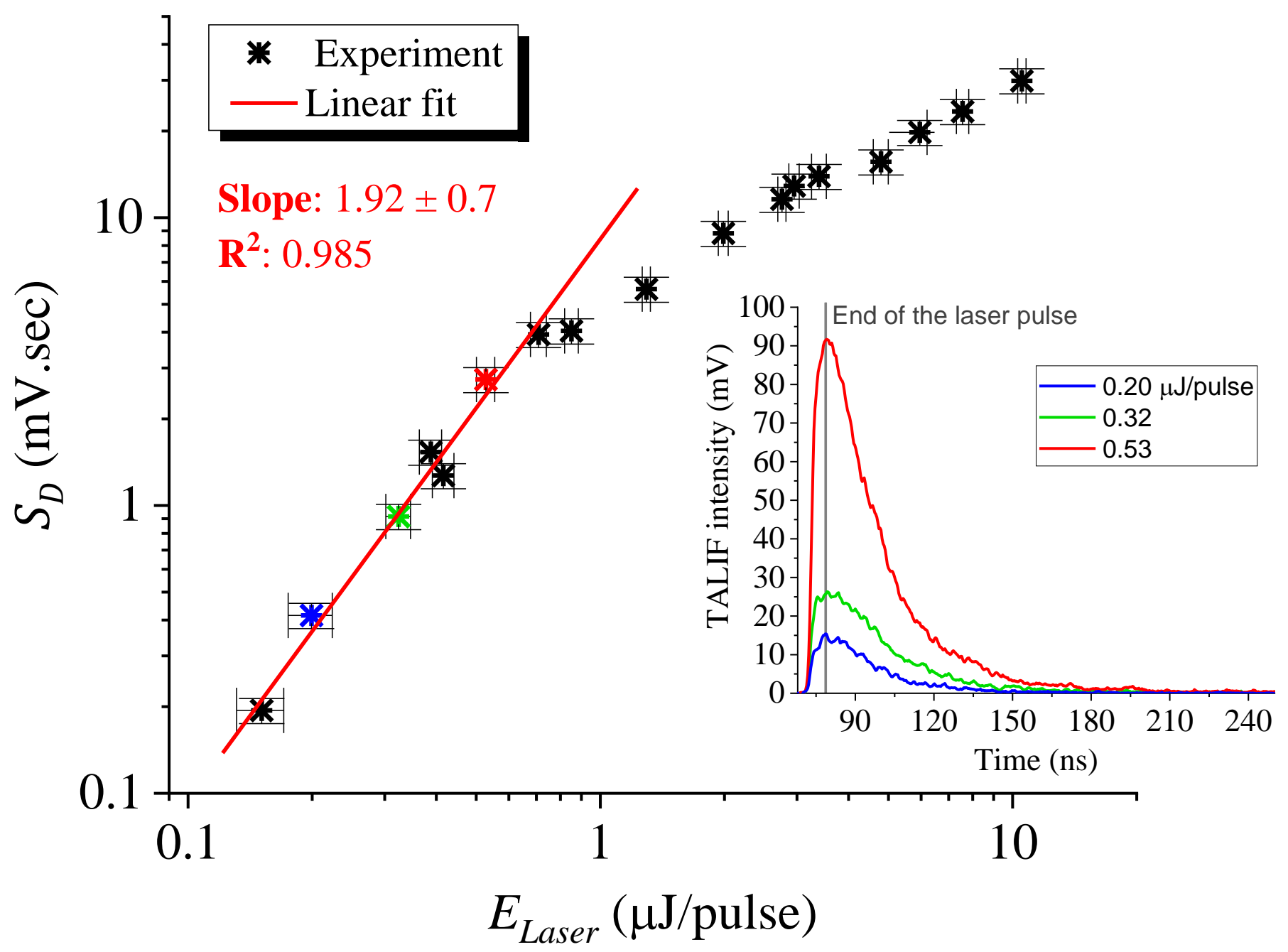

Figure 5. Time-integrated ps-TALIF signal $\left(S_{D}\right.$, stars) in $\mathrm{Kr}$ at $4 \mathrm{mbar}$ as a function of $E_{\text {Laser }}$. This was obtained by integrating TALIF signals such as those given in the inset for different $E_{\text {Laser }}$ (quadratic regime). These correspond to the colored stars in the $S_{D}$ plot versus $E_{\text {Laser }}$. 


\section{Fast (ns) and Ultrafast (ps/fs) TALIF: Probing Atomic Species in Plasmas, Flames, and/or Gases}

The unique features of TALIF spectroscopy have made it ideal for accessing absolute densities of reactive atoms (notably $\mathrm{H}, \mathrm{N}$, and $\mathrm{O}$ ) in plasmas and flames. Indeed, TALIF allows for the in situ, non-intrusive, and selective probing of those atoms with high spatial $(\mathrm{mm}-\mu \mathrm{m})$ and temporal (ns-fs) resolution [23,24]. Particularly, ps/fs-TALIF features are suitable for experiments carried out at intermediate and high pressures (atmospheric or higher), where the investigated media are described by relatively small dimensions and high spatio-temporal density gradients. Thus, a better understanding of species kinetics and production pathways in chemically reactive media can be reached. Ultimately, the use of fast and ultrafast TALIF may lead to the optimization and control of the production of reactive species for diverse applications, which can be achieved by manipulating critical operating parameters of plasmas and flames (e.g., electrode geometry, driving voltage amplitude, operating gas or gas mixture, air-fuel ratio, etc.). This section provides representative examples from the literature, which demonstrate the efficacy and necessity of fast (ns) and ultrafast (ps/fs) TALIF diagnostics for fundamental studies of plasmas and flames.

\subsection{Fast (ns) TALIF}

The first evidence of the pertinence of ns-TALIF for probing atomic hydrogen and deuterium was reported by Bokor et al. [33] in 1981. H atoms were excited from the $n=1$ to the $\mathrm{n}=3$ levels using two UV photons $(2 \times 205 \mathrm{~nm})$, and the subsequent fluorescence was detected at $656.3 \mathrm{~nm}$. $\mathrm{H}$-atom was produced by flowing mixtures of $\mathrm{H}_{2}$ and $\mathrm{D}_{2}$ in a $\mathrm{DC}$ discharge, and was probed by a tuneable $\mathrm{ArF}^{*}$ excimer laser. This work opened up new possibilities for probing by means of TALIF the atomic hydrogen as well as other reactive atomic species. Indeed, soon after that study, Bischel et al. demonstrated the capacity of ns-TALIF to probe $\mathrm{N}$ and $\mathrm{O}$ atoms in a flow discharge [34,35]. Ground-state $\mathrm{N}$ and $\mathrm{O}$ atoms were excited to the $2 \mathrm{p}^{2} 3 \mathrm{p}^{4} \mathrm{D}^{0}$ and $3 \mathrm{p}^{3} \mathrm{P}$ levels, respectively, using two UV photons $(2 \times 211 \mathrm{~nm}$ and $2 \times 226 \mathrm{~nm}$, respectively). The corresponding fluorescence signals were detected at $869 \mathrm{~nm}\left(2 \mathrm{p}^{2} 3 \mathrm{p}^{4} \mathrm{D}^{0} \rightarrow 2 \mathrm{p}^{2} 3 \mathrm{~s}^{4} \mathrm{P}\right.$ transition) and $845 \mathrm{~nm}\left(3 \mathrm{p}^{3} \mathrm{P} \rightarrow 3 \mathrm{~s}^{3} \mathrm{~S}\right)$. In [35], the natural lifetimes and quenching rate constants (considering $\mathrm{N}_{2}$ as quencher) of $\mathrm{N}$ and O atoms were measured. Around that time, Aldén et al. [37] demonstrated the capacity of ns-TALIF to detect atomic oxygen in a lean acetylene/oxygen flame. Following these pioneering works, numerous ns-TALIF studies were reported, for detecting $\mathrm{H}, \mathrm{N}$, and $\mathrm{O}$ atoms in flames and plasmas. Some relevant examples are given in this section.

In 1986, Meler et al. [86] used ns-TALIF to determine absolute number densities and collisional quenching rate constants (considering different quenchers such as $\mathrm{He}, \mathrm{Ar}$, $\mathrm{O}_{2}, \mathrm{H}_{2}, \mathrm{H}_{2} \mathrm{O}, \mathrm{CH}_{4}$, and $\mathrm{C}_{2} \mathrm{H}_{2}$ ) of $\mathrm{H}$ and $\mathrm{O}$ atoms in hydrogen-oxygen flames. Atomic absolute densities were obtained through comparison of the respective TALIF signal intensities with those obtained from known concentrations in a discharge flow reactor. Atomic collisional quenching rate constants were evaluated from fluorescence decay curves recorded at increasing concentrations of the quenchers. The range of pressures studied was 0.5-10 mbar. Furthermore, the authors showed the dependence on the gas temperature (293-698 $\mathrm{K}$ range) of the quenching rate constants of $\mathrm{H}$ and $\mathrm{O}$ atoms using different collision partners $\left(\mathrm{H}_{2}, \mathrm{H}_{2} \mathrm{O}, \mathrm{OH}, \mathrm{NO}, \mathrm{NO}_{2}\right.$, etc.). Laser-induced photolytic effects were possible at the highest laser power densities. A more detailed description of photochemical effects appearing during ns-TALIF application in hydrogen-oxygen flames was studied in [73]. In an atmospheric pressure flame, high $\mathrm{O}$-atom densities were measured in the post-flame gases, and increased at higher laser power densities. However, in the case of a 72 Torr flame, photochemical production of O atoms was negligible. In 1991, Westblom et al. [46] investigated low- and high-pressure nitrogen-containing flames (such as $\mathrm{NH}_{3} / \mathrm{O}_{2}$ flames). They demonstrated that atomic nitrogen can be detected in those flames using ns-TALIF. They also found that $\mathrm{N}$-atom can both be produced by the flame alone and by laserinduced photodissociation of nitrogen-containing molecules, which was induced by the 
laser radiation. Similarly, H-atom TALIF was performed in [98] to investigate the role of laser-induced molecular dissociation in the production of $\mathrm{H}$ atoms in silane and methane plasmas. The formation of $\mathrm{H}$ atoms through photodissociation by the laser was dominant with respect to that owed to the discharge alone.

The determination by ns-TALIF of $\mathrm{H}$-atom concentration $\left(\mathrm{N}_{\mathrm{H}}\right)$ in a $10 \mathrm{MHz}$ discharge operating in pure hydrogen at 3 Torr was achieved in [63]. The authors performed axial and temporal measurements of $\mathrm{N}_{\mathrm{H}}$ along the interelectrode gap (19 $\mathrm{mm}$ ) with a spatial resolution of $100 \mu \mathrm{m}$. The calibration of the TALIF signals was done in a discharge flow reactor using a titration technique (for more details, see also [41]). The experiments were coupled to a numerical diffusion model, revealing that diffusion from the source to the interelectrode region determined the distribution of plasma-produced $\mathrm{H}$ atoms. When the discharge was turned off, diffusion to the electrode surfaces determined the steady-state density and the decay of $\mathrm{H}$ atoms. In 1998, Adams et al. [66] proposed a better TALIF excitation scheme for atomic nitrogen compared to that used in earlier works. N-atom production was achieved using a microwave flowing $\mathrm{N}_{2}$ discharge generated in a quartz tube. In fact, instead of considering a $2 \times 211 \mathrm{~nm}$ excitation of ground-state $\mathrm{N}$ atom to the $2 \mathrm{p}^{2} 3 \mathrm{p}^{4} \mathrm{D}^{0}$ level, and subsequent fluorescence detection at $869 \mathrm{~nm}\left(2 \mathrm{p}^{2} 3 \mathrm{p}^{4} \mathrm{D}^{0} \rightarrow 2 \mathrm{p}^{2} 3 \mathrm{~s}^{4} \mathrm{P}\right)$, they used a $2 \times 207 \mathrm{~nm}$ excitation to the $3 \mathrm{p}^{4} \mathrm{~S}_{3 / 2}^{0}$ level, and fluorescence detection at $745 \mathrm{~nm}$ $\left(3 \mathrm{p}^{4} \mathrm{~S}_{3 / 2}^{0} \rightarrow 3 \mathrm{~s}^{4} \mathrm{P}\right)$. The two-photon excitation rate at $207 \mathrm{~nm}$ was 3.5 times larger than that at $211 \mathrm{~nm}$. Moreover, the ratio of the corresponding TALIF signal intensities $\left(\mathrm{I}_{207} / \mathrm{I}_{211}\right)$ was of $8.6 \pm 0.9$ and $14.8 \pm 1.5$ at 2 and 6 Torr, respectively. Consequently, this N-TALIF scheme has been widely employed in subsequent works. In another study, Goehlich et al. [92] used ns-TALIF and titration methods, and managed to measure with 50\% uncertainty the ratio between the two-photon absorption cross-sections $\left(\sigma^{(2)}\right)$ of $\mathrm{Xe}$ and $\mathrm{O}$ atoms. This was a novel calibration technique at that time, which facilitated the measurement by means of ns-TALIF of the O-atom absolute density in a capacitively coupled $\mathrm{rf}$ discharge. In 2001, Niemi et al. [36] used similar methods and obtained useful $\sigma^{(2)}$ ratios (also with 50\% uncertainty) for the following pairs of atomic species: $\mathrm{Kr}-\mathrm{H}, \mathrm{Kr}-\mathrm{N}$, and $\mathrm{Xe}-\mathrm{O}$ (for more details on the ratio values, refer to the previous section). Additionally, they were able to evaluate the natural lifetimes and the quenching coefficients (using $\mathrm{H}_{2}, \mathrm{~N}_{2}, \mathrm{O}_{2}, \mathrm{He}, \mathrm{Ar}, \mathrm{Kr}$, $\mathrm{Xe}$, and $\mathrm{CH}_{4}$ as quenchers) of the following commonly encountered fluorescing atomic states: $\operatorname{Kr}\left(5 \mathrm{p}^{\prime}[3 / 2]_{2}\right), \mathrm{H}\left(3 \mathrm{~d}^{2} \mathrm{D}_{J}\right), \mathrm{N}\left(3 \mathrm{~s}^{4} \mathrm{P}_{3 / 2}\right), \mathrm{Xe}\left(7 \mathrm{p}[3 / 2]_{2}\right)$, and $\mathrm{O}\left(3 \mathrm{p}^{3} \mathrm{P}_{J}\right)$.

Following the works of Goehlich et al. [92] and Niemi et al. [36], numerous research groups have been using ns-TALIF for studying different discharge plasmas. In 2002, Mazouffre et al. [67] investigated the production of $N\left({ }^{4} S\right)$ atoms in a thermal $\mathrm{N}_{2}$ plasma jet. Both axial and radial density measurements were performed, which were coupled with ax$\mathrm{ial} /$ radial atomic temperature and velocity profiles, allowing for the kinetics of $\mathrm{N}\left({ }^{4} \mathrm{~S}\right)$ atom to be analyzed. In 2005, the accuracy of the measured value of the two-photon absorption cross-section ratio of $\sigma^{(2)} \mathrm{Xe} / \sigma^{(2)} \mathrm{O}$ from [36,92] was improved by Niemi et al. [78] (see previous section for corresponding values). The authors also performed measurements of the absolute $\mathrm{O}$-atom density, quenching coefficients by $\mathrm{He}, \mathrm{Ar}$, and $\mathrm{O}_{2}$, and radiative lifetimes of $\mathrm{O}$ atoms in the effluent of a $\mathrm{He}-\mathrm{O}_{2} \mathrm{rf}$ atmospheric pressure plasma jet (APPJ). Similarly, O-TALIF studies coupled with optical emission spectroscopy (OES) were performed in a planar rf $\mathrm{He}-\mathrm{O}_{2}$ plasma jet [99]. The measured $\mathrm{O}$-atom density close to the jet's nozzle was of $\sim 10^{16} \mathrm{~cm}^{-3}$ decreasing by $99 \%$ at a distance of $10 \mathrm{~cm}$ from the nozzle, which was also supported by OES studies of excited $\mathrm{O}$ atoms. The quantification via ns-TALIF of $\mathrm{N}$ atoms in an atmospheric pressure $\mathrm{N}_{2}$ dielectric barrier discharge (DBD) was reported in [100]. Studies were performed under two discharge modes, i.e., homogeneous and filamentary. For both modes, the maximum densities reached values up to $3 \times 10^{14} \mathrm{~cm}^{-3}$ (measured with 25\% accuracy). The density in the case of the homogeneous discharge was measured versus the axial position, the gas flow rate, and the power dissipated in the plasma. The parameter which governed the $\mathrm{N}$-atom production was the power/energy dissipated in the plasma. Furthermore, in 2012, Teramoto et al. [101] used ns-TALIF to probe $\mathrm{N}$ atoms produced by a pulsed atmospheric pressure corona discharge operating 
with $\mathrm{N}_{2}$ or $\mathrm{N}_{2} / \mathrm{O}_{2}$ gases. The laser beam was spread to obtain a laser sheet covering a discharge volume of $10 \mathrm{~mm}$ in length, $2 \mathrm{~mm}$ in width, and $0.1 \mathrm{~mm}$ in thickness. Both spaceand time-resolved density measurements were performed. The atomic nitrogen absolute density increased with the discharge energy and decreased with increasing distance from the powered electrode. For a $\mathrm{N}_{2}$ discharge, the production of $\mathrm{N}$ atoms happened during the primary streamer event, while for a $\mathrm{N}_{2} / \mathrm{O}_{2}$ discharge, it happened during the secondary streamer event.

The spatial distribution of laser-excited atomic oxygen in a RF Ar/Air APPJ was investigated in [102]. All measurements were performed $10 \mu \mathrm{s}$ after the plasma was switched off to avoid the strong time-modulated background from the plasma emission, which reduced the TALIF signal-to-noise ratio. The spatial resolution was of $100 \mu \mathrm{m}$ and $1 \mathrm{~mm}$ in the radial and axial direction, respectively. The effect on the quenching of $\mathrm{O}\left(3 \mathrm{p}^{3} \mathrm{P}_{J}\right)$ atom of the varying air concentration in the jet was studied. It was shown that the collisional quenching by air depends on the radial/axial distance from the jet's nozzle, and needs to be taken into account when performing spatially resolved $\mathrm{O}$-atom density measurements with TALIF. Mrkvičková et al. [64] determined the absolute density of $\mathrm{H}$ atoms in a pulse-modulated $\mathrm{Ar} / \mathrm{H}_{2}$ surface DBD operating at atmospheric pressure. The authors were able to record both space- and time-resolved $\mathrm{H}$-atom densities. The plotted temporal/tangential distribution of $\mathrm{H}$-atom concentration at a distance of $1 \mathrm{~mm}$ above the dielectric surface revealed significant temporal/spatial density gradients. Finally, we mention two characteristic ns-TALIF studies, which were published very recently. First, Yue et al. [42] determined the absolute density of $\mathrm{H}$ atoms in a $1 \mathrm{kHz}$-modulated $\mathrm{rf}$-driven plasma jet in $\mathrm{He}-\mathrm{H}_{2}$. The generation, transport, and decay of $\mathrm{H}$ atoms along the jet axis were effectively measured, and the obtained results were reproduced by a pseudo-1D numerical model. The effect on the $\mathrm{H}$-atom density of the power modulation was not significant in the plasma effluent, being mainly noticeable in the plasma generation zone. Second, Chng et al. [72] evaluated the absolute density of $\mathrm{N}$ atoms in the afterglow of a nanosecond capillary discharge operating in $\mathrm{N}_{2}$ at 27 mbar. The experiments were supported by numerical calculations, improving the understanding of $\mathrm{N}$-atom kinetics in this discharge type. Their measurements revealed a maximal $\mathrm{N}$-atom density of $1.29 \times 10^{17} \mathrm{~cm}^{-3}$, corresponding to a dissociation degree of $\sim 9.7 \%$, while the energy efficiency of the atomic nitrogen production was of 10 atoms $/ 100 \mathrm{eV}$.

\subsection{Ultrafast ( $p s / f s)$ TALIF}

In many cases, chemically reactive media such as plasmas and flames are characterized by strong spatial and temporal gradients of the density of reactive species. In these media, the collisional frequency increases with increasing pressure, and species lifetimes decrease drastically depending on the nature of the investigated species and quenchers [36]. Under these conditions, the use of ultrafast instead of fast lasers is preferable for a more reliable evaluation of species quenching rate constants, lifetimes, and absolute densities. This section provides representative examples from the literature, demonstrating the suitability of ultrafast fluorescence spectroscopy for studying atomic species kinetics in flames and plasmas.

The first use of an ultrafast fluorescence technique was reported by Bergano et al. in 1983 [103], assessing collisional quenching rates and lifetimes of OH radicals in atmospheric pressure methane-air flames. The width of the laser pulse used was of $5 \mathrm{ps}$ and the laser spectral bandwidth was of $0.03 \mathrm{~nm}$. Ground-state $\mathrm{OH}$ radicals were excited at $307 \mathrm{~nm}$. The fluorescence signal was recorded with a streak camera with a temporal resolution of $\sim 150 \mathrm{ps}$. That work opened up new possibilities on the application of ultrafast fluorescence spectroscopy to the experimental study of chemically reactive media. Indeed, using psTALIF, Agrup et al. [47] investigated the fluorescence and the amplified stimulated emission (ASE) from $\mathrm{O}$ atoms in a $\mathrm{H}_{2} / \mathrm{O}_{2}$ flame. The width of the laser pulses was of $10 \mathrm{ps}$ and the laser pulse energy of $40 \pm 20 \mu \mathrm{J}$. ASE was produced due to a laser-induced population inversion between the two excited levels of $\mathrm{O}$ atom, increasing along the laser beam. 
ASE was measured using a streak camera, revealing a similar temporal shape to that of the leading edge of the laser pulse. The fluorescence signal intensity was much weaker compared to that of ASE, and was recorded using a photomultiplier tube (1 ns time resolution). The lifetime of the fluorescing atomic state was measured to be between $160 \pm 20$ ps and $1 \mathrm{~ns}$. The same group used ps-TALIF and performed measurements of the collisional quenching of $\mathrm{H}$ atoms in an atmospheric pressure $\mathrm{H}_{2} / \mathrm{O}_{2}$ flame [48]. The fluorescence signal was recorded by means of a streak camera offering a temporal resolution of a few ps. The lifetime of the laser-excited $\mathrm{H}$ atom varied between 60 and $105 \mathrm{ps}$ in the reaction zone of the flame, while it was of 90 ps in the post-flame region. Similarly to the previous study, ASE presented a high magnitude and led to a significant depletion of the laser-excited state. ASE happened mostly within the laser pulse duration, and extended to a duration of about 50 ps after the end of the laser pulse.

In 2003, Settersten et al. [89] studied by means of ps-TALIF (laser pulse duration of $55 \mathrm{ps}, 1 \mathrm{~cm}^{-1}$ linewidth) the formation of atomic oxygen in hydrocarbon flames. They aimed particularly for the identification of photolytic precursor molecules perturbing the TALIF signal. The laser beam diameter in the measurement volume was of $60 \mu \mathrm{m}$ and the laser pulse energy of $3 \mu \mathrm{J}$. Experiments were coupled with a one-dimensional flame model, and showed significant interferences from vibrationally excited $\mathrm{CO}_{2}$ at the fuel side of the flame. Shortly after, Frank et al. [51] used ps-TALIF and performed spatially- (twodimensional) and temporally-resolved mappings of $\mathrm{O}$ atoms in a $\mathrm{CH}_{4} / \mathrm{O}_{2} / \mathrm{N}_{2}$ flame with negligible photolytic interference. The recorded O-TALIF signals provided accurate measurements of $\mathrm{O}$ atom profiles in the flame. Kulatilaka et al. [53] achieved interference-free planar (by creating a laser sheet) ps-TALIF experiments and determined the atomic hydrogen density in $\mathrm{CH}_{4} / \mathrm{O}_{2} / \mathrm{N}_{2}$ flames. The laser sheet dimensions were of $2.5 \mathrm{~mm} \times 200 \mu \mathrm{m}$. In this case, the laser fluence was less than $0.08 \mathrm{~J} . \mathrm{cm}^{-2}$. The single-shot atomic density detection limit was of $10^{16} \mathrm{~cm}^{-3}$ for equivalence ratios between 0.8 and 1.5 . After recording H-atom TALIF signals at different axial positions along the flame, the authors constructed averaged 2D H-atom TALIF images of the flames. These revealed enhanced H-atom densities at the flame tip. Finally, our group has recently initiated ps-TALIF studies (10 ps laser pulses) in $\mathrm{Kr}$ gas in order to define conditions (in terms of laser intensity) allowing for the quadratic regime to be obtained [97]. Our results suggest that, for laser intensities well-below than $18 \mathrm{MW} \cdot \mathrm{cm}^{-2}, \mathrm{Kr}$ atom can be used as a calibrating species for measuring by means of ps-TALIF the absolute densities and quenching coefficients of $\mathrm{H}$ and $\mathrm{N}$ atoms in plasmas and flames.

With respect to fs-TALIF application in flames and gases, the spatial imaging of atomic hydrogen in a $\mathrm{CH}_{4} / \mathrm{O}_{2} / \mathrm{N}_{2}$ flame was achieved using planar fs-TALIF [54]. The peak laser pulse energy was of $8 \mu \mathrm{J}$ at $205 \mathrm{~nm}$. The laser beam was collimated to a diameter of about $1 \mathrm{~mm}$ before going through the flame. The experimental $\mathrm{H}$-atom profiles were recorded at different laser pulse energies $(0.25-7.3 \mu \mathrm{J})$ and heights above the nozzle of the burner (3.5-15.5 mm), revealing negligible photolytic interferences. This was also confirmed by a time-dependent 2D model capable of simulating unsteady reacting flows. Furthermore, in a more recent study [104], the use of fs-TALIF only in $\mathrm{Kr}$ gas allowed the authors to perform single-shot 2D planar images of $\mathrm{Kr}$ atoms in a gas cell. The laser pulse duration was of about $80 \mathrm{fs}$ at $1 \mathrm{kHz}$ repetition rate, and the maximum laser pulse energy was of $13 \mu \mathrm{J}$ at $204.1 \mathrm{~nm}$ (i.e., the two-photon excitation wavelength used for $\mathrm{Kr}$ ). For laser pulse energies lower than $4 \mu \mathrm{J}$, the two-photon excitation of $\mathrm{Kr}$ did not reach saturation nor loss of the fluorescence signal due to ASE or photoionization. This work revealed the potential of fs-TALIF to be used as a diagnostic method in mixing and flow studies using $\mathrm{Kr}$ as a tracer. The authors demonstrated its feasibility by performing 2D planar fs-TALIF images of $\mathrm{Kr}$ atoms in a $\mathrm{Kr}$ gas jet.

Contrary to what has been done in flames, the use of ultrafast TALIF diagnostics in plasmas is only very recent. In 2015, Schmidt et al. [45] employed a fs-TALIF diagnostic to record the spatial distribution of atomic oxygen in an atmospheric-pressure capillarydielectric-barrier-discharge (CDBD). The plasma was formed in a $\mathrm{He}-\mathrm{O}_{2}$ gas mixture by 
applying microsecond high-voltage pulses to the electrodes. The width of the laser pulse was of $\sim 100 \mathrm{fs}$ and the laser pulse energy was of $13 \mu \mathrm{J}$. The calibration of the $\mathrm{O}$-atom density measurements was carried out using fs-TALIF in Kr. Planar TALIF was performed by constructing a laser sheet $(2 \mathrm{~mm}$ tall with a beam waist of $0.09 \mathrm{~mm}$ focused on the plasma effluent). This allowed to perform a detailed 2D mapping of the $\mathrm{O}$-atom density in the plasma effluent. From this mapping, the maximum O-atom absolute density at the plasma axis was found to be of $6 \times 10^{15} \mathrm{~cm}^{-3}$. Noticeable density gradients along the radial direction were also revealed. Furthermore, in 2017 the same group published two works on the implementation of the same fs-TALIF system for the investigation of non-equilibrium plasmas. In their first study [91], they performed temporally and spatially resolved imaging of the density of $\mathrm{H}$ and $\mathrm{O}$ atoms in a ns-pulsed pin-to-pin discharge. The discharge was generated in $\mathrm{H}_{2} / \mathrm{He}, \mathrm{H}_{2} / \mathrm{Ar}$ and $\mathrm{O}_{2} / \mathrm{He}$ gas mixtures at a total pressure of 100 Torr. The experiments were coupled with a quasi-1D model taking into account the Poisson, Boltzmann, and non-equilibrium plasma chemistry kinetics equations. From the constructed 2D absolute density maps, the local $\mathrm{H}$-atom number densities varied between $2 \times 10^{12}$ and $6 \times 10^{15} \mathrm{~cm}^{-3}$, while the $\mathrm{O}$-atom densities were found between $10^{13}$ and $3 \times 10^{16} \mathrm{~cm}^{-3}$. The authors also measured the decay rates and lifetimes for both atoms. The latter were of $\sim 100 \mu$ s and $1 \mathrm{~ms}$ for $\mathrm{H}$ and $\mathrm{O}$ atoms, respectively, in a relatively good agreement with the numerical model. In their second study [90], the authors used the same plasma as in [45], and performed a comparison of the efficacy and accuracy of fsand ns-TALIF on the absolute density determination of atomic oxygen absolute densities. The superiority of the fs-TALIF as a more accurate diagnostic method of the CDBD was demonstrated (see also next section).

Regarding studies from other research groups, the possibility of implementing a psTALIF diagnostic for measuring $\mathrm{H}, \mathrm{N}$, and $\mathrm{O}$ atomic densities in a rf-driven atmosphericpressure plasma jet was presented in 2016 in the APIP conference [105]. The plasma was generated in different mixtures of helium gas with $\mathrm{O}_{2}, \mathrm{~N}_{2}$, and water. The limitations of ns-TALIF when determining those species densities at atmospheric pressure were discussed. To overcome these limitations, the authors proposed the use of ps-TALIF, being capable of resolving the effective lifetime of excited atoms, and measuring accurately their absolute densities. Some of those results were published in the mid-2020 [44]. Specifically, the authors focused on the formation of $\mathrm{H}$ and $\mathrm{O}$ atoms in a $\mathrm{He} / \mathrm{H}_{2} \mathrm{O}$ plasma jet. The plasma was probed using ps laser pulses ( $30 \mathrm{ps}$ duration) at a repetition rate of $10 \mathrm{~Hz}$. The laser pulse energies used for measuring $\mathrm{H}$ - and $\mathrm{O}$-atom densities were of 35 and $24 \mu \mathrm{J}$, respectively, and the laser spectral bandwidth was of about $4 \mathrm{~cm}^{-1}$. The absolute densities of $\mathrm{H}$ and $\mathrm{O}$ atoms reached values of $6 \times 10^{14} \mathrm{~cm}^{-3}$ and $4.3 \times 10^{13} \mathrm{~cm}^{-3}$, respectively. Possible errors on the density determination were analyzed, reaching $58 \%$ and $39 \%$ for $\mathrm{H}$ and $\mathrm{O}$ atom, respectively, mostly due to the uncertainty of the available values of $\sigma^{(2)}$ (see previous section). Furthermore, the quenching rate constants by $\mathrm{H}_{2} \mathrm{O}$ of $\mathrm{H}(\mathrm{n}=3)$ and $\mathrm{O}\left(3 \mathrm{p}^{3} \mathrm{P}\right)$ laser-excited atoms were experimentally obtained, being of $6 \times 10^{-9}( \pm 3 \%)$ and $1.1 \times 10^{-9}( \pm 10 \%) \mathrm{cm}^{3} \cdot \mathrm{s}^{-1}$, respectively. The experiments were coupled with a $0 \mathrm{D}$ chemical kinetics model, which allowed investigating the production mechanisms of $\mathrm{O}$ and $\mathrm{H}$ atoms in the plasma effluent. In 2019, Dumitrache et al. [62] investigated by means of fs-TALIF the production of $\mathrm{N}$ atoms in a ns repetitive discharge (NRP). The laser pulse duration was of $\sim 100 \mathrm{fs}$ with an average pulse power of $\sim 7$ Watts at a repetition frequency of $1 \mathrm{kHz}$. The laser beam at the focal point had a waist of $50 \mu \mathrm{m}$. The capacity of measuring $\mathrm{N}$-atom fs-TALIF signals in the pressure range $0.1-5$ bar was demonstrated. However, saturation phenomena were observed, which were due to a significant photoionization of the laser-excited $\mathrm{N}$ atom by a third laser photon (this was also the case for fs-TALIF in $\mathrm{Kr}$ gas). Thus, photoionization led to a departure from the quadratic regime of excitation, preventing quantitative density measurements (see also next section). To overcome this issue, the authors presented a novel calibration method in a subsequent work [43]: instead of using $\mathrm{Kr}$ as a calibrating gas, the calibration was done based on direct VUV absorptionspectroscopy measurements of $\mathrm{N}$-atom performed in a low-pressure DC discharge. The 
determination of $\mathrm{N}$-atom density by means of fs-TALIF was performed at 1 bar in the post discharge of the NRP. A maximum density of $5 \times 10^{16} \mathrm{~cm}^{-3}$ was obtained at $1 \mu \mathrm{s}$ after the nanosecond pulse while the discharge was operating in pure $\mathrm{N}_{2}$. The lower limit of detection of the $\mathrm{N}$-atoms was determined to be of $10^{12} \mathrm{~cm}^{-3}$.

\section{Challenges on the Use of Fast (ns) and Ultrafast (ps/fs) TALIF for Diagnostic Purposes}

Despite the great potential of ns- and ps/fs-TALIF for diagnostic purposes in plasmas and flames, several limitations can make their implementation challenging. First, nsTALIF is in general reliable for absolute density measurements at pressures lower than 10 mbar [29]. However, with increasing pressure, the collisional quenching can become the major loss mechanism of excited states of interest depending on the species and the quencher nature [36]. As an example, the quenching time of excited $\mathrm{H}$ atoms in flames can fall well below ns at atmospheric pressure [47], being faster than the pulse duration of ns lasers (typically few ns). In this case, to infer the quenching rate and effective lifetime of species from the fluorescence signal, the use of adequate models can be helpful on the correction of the TALIF signal $[32,65,106]$. However, the development of those models is based on different assumptions, limiting thus their accuracy. Furthermore, for fast nspulsed discharges with voltage pulse durations lower than $10 \mathrm{~ns}$ and rise/fall times of the order of few ns $[19,32,107]$, ns-TALIF does not allow investigating species kinetics during the voltage pulse. Thus, ns-TALIF (and LIF) can only be useful to perform time-resolved measurements on longer time-scales than the laser pulse duration, i.e., several tens of ns, $\mu$ s or ms time-scales $[32,36,72,102]$. For accurate measurements in sub-ns time-scales, a better approach would be to use ultrafast lasers. These can deliver (1) pulse widths down to the ps and fs time-scales, and (2) sufficient instantaneous laser intensities (units $\mathrm{W} \cdot \mathrm{cm}^{-2}$ ) to achieve the necessary two-photon transitions.

Furthermore, compared to the species single-photon absorption cross-sections required in LIF, the two-photon absorption cross-sections in TALIF are much lower, which makes difficult the detection of TALIF signals with high signal-to-noise ratio. In ns-TALIF, this issue can be resolved by increasing the laser intensity. However, this may lead to a significant laser-induced dissociation of different molecules in the probed medium, photoionization (PIN), and/or amplified stimulated emission (ASE), substantially perturbing the TALIF signal, and reducing the fluorescence yield. Compared to ns lasers, ultrafast lasers present much higher instantaneous and similar average powers. However, the use of ultrafast TALIF on the study of transient plasmas, which can present steep density gradients within $\mu \mathrm{m}$-scale dimensions, would require tightly focused laser beams in order to reach the desired spatial resolution. Again, this would result in a significant increase in the laser intensity, possibly leading to photolytic effects and depletion of the laser-excited states by PIN and/or ASE. Therefore, appropriate solutions should be found, e.g., instead of using tightly focused laser beams, to spread the laser energy in a plane (i.e., creating a laser sheet) in order to reduce the laser intensity for the same laser peak pulse power [45,104]. Another effect of a high laser intensity can be the saturation of the optical transition, which is known as power saturation [3]. In this case, the optical pumping rate of the laser excited-state can become comparable to its relaxation rate. To avoid a significant depletion of the ground state of the species of interest, the inverse of the two-photon absorption rate (i.e., $1 / W_{E 1 \rightarrow E 2}(t)$, units in sec, see Section 2.1) must be much higher than the pulse width of the laser [55]. Based on the above information, this section gives representative examples from the literature, where limitations on the reliable use of TALIF have been encountered, reported, and discussed.

\subsection{Challenges When Using ns-TALIF in Flames and Gases}

The onset of laser-induced dissociation, PIN and ASE effects has been investigated in different early studies on ns-TALIF in flames [38,49,73,108]. For instance, in [73], ns-TALIF was used to quantify atomic oxygen in hydrogen-oxygen flames. In a lean atmosphericpressure flame, artificially high O-atom concentration was measured in the post-flame 
gases. According to the authors, the excess atomic oxygen amount was produced by single-photon excitation of vibrationally excited $\mathrm{O}_{2}$ molecules. The production of $\mathrm{O}$ atoms from other precursor molecules in the flame was not excluded. The effect of increasing the laser intensity on the excessive production of $\mathrm{O}$ atoms was demonstrated. In fact, by increasing the laser intensity by 300 times, the $\mathrm{O}$-atom density as a function of the height above the burner became almost flat, suggesting that $\mathrm{O}$-atom creation proceeded through photodissociation of precursor molecules, which were present in the post-flame gases. In another study [108], the influence of ASE (recorded end-on with respect to the laser beam) on the $\mathrm{O}$-atom TALIF (recorded side-on) in a $\mathrm{H}_{2} / \mathrm{O}_{2}$ flame and room-temperature gases $\left(\mathrm{O}_{2}\right.$ and $\left.\mathrm{N}_{2} \mathrm{O}\right)$ was investigated. For the three conditions, the ASE signal intensity increased with the laser intensity being much stronger than the TALIF signal intensity. This led to a rapid depletion of the laser-excited $\mathrm{O}$ atom level and a decrease in the fluorescence yield. As it was discussed at the end of Section 2.1, for reliable TALIF measurements, the quadratic regime must be ensured (i.e., a slope of 2 in Figure 5). In [108], however, the slopes from the linear regressions of the experimental TALIF data points versus $\mathrm{E}_{\text {Laser }}$ were of 1.59, 2.95, and 4.14 for the $\mathrm{H}_{2} / \mathrm{O}_{2}$ flame, the $\mathrm{N}_{2} \mathrm{O}$ and $\mathrm{O}_{2}$ gases, respectively. The authors also underlined that the lower measured slope could also be due to a rapid depletion of the laser-excited state by PIN and/or partial saturation of the two-photon transition at high $\mathrm{E}_{\text {Laser }}$. The other two slopes were consistent with one- and two-photon photo-dissociation of $\mathrm{N}_{2} \mathrm{O}$ and $\mathrm{O}_{2}$ molecules, respectively, followed by two-photon excitation of atomic $\mathrm{O}$, which should give slopes of 3 and 4 , respectively. Thus, to avoid saturation effects, $E_{\text {Laser }}$ needed to be reduced significantly. Furthermore, in [38], ASE was recorded when probing by means of ns-TALIF the atomic hydrogen production in low-pressure flames. The behavior of ASE was compared to that of TALIF and its effect on the fluorescence quantum yield was demonstrated. ASE significantly reduced the fluorescence yield for $\mathrm{E}_{\mathrm{Laser}}>\sim 250 \mu \mathrm{J}$, the corresponding slope being lower than 2 . However, for $\sim 130<\mathrm{E}_{\text {Laser }}<250 \mu \mathrm{J}$, the quadratic regime was attained, while the intensity of ASE was one order of magnitude lower than that observed at $\mathrm{E}_{\text {Laser }}>250 \mu \mathrm{J}$. Finally, Alekseev et al. [109] performed ns-TALIF in a static gas cell and studied ASE signal intensity from $7 \mathrm{p}$ and $6 \mathrm{p}^{\prime}$ excited states of Xe atoms. They also measured the total quenching rate constants of those excited states by different quenching partners. The intensity of ASE decreased significantly with decreasing $\mathrm{E}_{\text {Laser }}$ and length of the gas cell, as well as when using unfocused laser beams. Furthermore, ASE decreased noticeably when lowering the gas pressure below 2 Torr. Based on these facts, the authors developed adequate experimental conditions to avoid interferences from ASE. Therefore, to avoid significant contributions from laser-induced photodissociation, ASE and PIN, which lead to saturated TALIF regimes, the laser intensity must be carefully selected to values leading to a quadratic dependence of the TALIF signal intensity versus the laser pulse energy.

\subsection{Challenges When Using ps/fs-TALIF in Flames and Gases}

Departures from the quadratic regime have also been observed when using ps-TALIF in flames. Agrup et al. [48] studied the production of atomic hydrogen in a hydrogenoxygen flame. The variations of the TALIF and ASE signal intensities versus the laser pulse energy (up to $32 \mu \mathrm{J}$ ) were recorded. For the lower power density (corresponding to laser pulse energies between 1.6 and $6.3 \mu \mathrm{J}$ ), a slope of $2.42 \pm 0.24$ was measured for the TALIF signal, which revealed that a portion of $\mathrm{H}$ atoms was produced by photolysis of water molecules. For laser pulse energies between 16 and $32 \mu \mathrm{J}$, the TALIF slope decreased to $0.62 \pm 0.09$. This was very close to the slope obtained for ASE, i.e., $0.63 \pm 0.14$, which perturbed the TALIF signal at the same energy range. The authors concluded that the development of a complex rate-equation model, including ionization, TALIF, photodissociation, quenching, and ASE processes, as well as the temporal profile of the laser pulse, was necessary to obtain absolute densities of $\mathrm{H}$ atoms in that flame. Such a model was not performed in that study. On the other hand, Frank et al. [52] compared nsand ps-TALIF when probing atomic oxygen in premixed hydrogen and methane flames. 
From the shape of the fluorescence-signal radial profiles in the flames, the perturbation from photolytic effects of the TALIF signal was not significant in the case of ps-TALIF. This low perturbation happened for laser fluences lower than $0.3 \mathrm{~J} \cdot \mathrm{cm}^{-2}$, as it was revealed from plots of the TALIF signal intensity versus the laser pulse energy, from which the quadratic regime was obtained. Similarly, a low photolytic perturbation was seen when studying methane flames, for which, however, the use of ns-TALIF resulted in significant photolytic effects at all laser energies studied. The ns- and ps-TALIF signal intensities were comparable between them, but the average laser fluence when using the ps laser was only $9 \%$ of that of the ns laser. Thus, the authors proposed ps-TALIF as a promising method for probing atomic oxygen in hydrocarbon flames. The same type of comparison was performed by Kulatilaka et al. [88] referring, though, to the detection of atomic hydrogen in the following premixed flames: $\mathrm{CH}_{4} / \mathrm{O}_{2} / \mathrm{N}_{2}, \mathrm{H}_{2} / \mathrm{O}_{2}$, and $\mathrm{H}_{2} / \mathrm{O}_{2} / \mathrm{N}_{2}$. The aim of that study was to develop an interference-free diagnostic method of $\mathrm{H}$ atoms using much shorter laser pulses than those used conventionally. Different radial profiles of $\mathrm{H}$ atoms were recorded both with ns- (3.5 ns laser pulse) and ps-TALIF (70 ps laser pulse). Distortions of the recorded TALIF signals by photolytic effects and ASE were investigated. When ps-TALIF was used, the interference from ASE was the most significant effect, lowering the ps-laser fluence threshold needed for $\mathrm{H}$-atom interference-free detection. Nevertheless, the potential of ps-TALIF to be used for probing $\mathrm{H}$ atoms in hydrogen and methane flames was demonstrated. In fact, when ASE was not significant, the intensities of the ps-TALIF signals were about one order of magnitude higher than those obtained using ns-TALIF. Furthermore, latest studies performed by our group on the use of ps-TALIF in Kr gas, revealed that the TALIF signal is significantly affected by PIN when the instantaneous laser intensity is $>15 \mathrm{MW} \cdot \mathrm{cm}^{-2}$ [97]. On the other hand, the intensity of ASE was only significant within the laser pulse ( $10 \mathrm{ps})$ and the total number of photons attributed to ASE was much lower than the time-integrated TALIF signal. Therefore, it was concluded that PIN determines the population of the fluorescing state and, thus, the TALIF signal intensity beyond the quadratic regime [97]. Another promising approach to avoid those interferences could be the consideration of fs-TALIF. Indeed, the use of fs-TALIF for the 1D/2D imaging of atomic hydrogen in hydrocarbon flames was reported in [54]. The authors demonstrated that this technique allows avoiding photolytic effects in the case of $\mathrm{H}$ atom, while they proposed that can be employed for probing other atoms as well (such as $\mathrm{O}$ and N) both in flames and plasmas. Furthermore, in 2017, the same group reported on the efficacy of fs-TALIF for the imaging of $\mathrm{Kr}$ atoms in a $\mathrm{Kr}$ gas jet, which can be a useful species as an inert gas tracer in flow diagnostic studies. The quadratic regime was obtained for laser pulse energies between 1 and $3 \mu \mathrm{J}$, revealing that the two-photon excitation scheme of $\mathrm{Kr}$ was not affected by ASE, PIN, and saturation effects. This was encouraging for later uses of $\mathrm{Kr}$ (and $\mathrm{Xe}$ ) as calibrating species in order to perform absolute density measurements of $\mathrm{H}$ (and $\mathrm{O}$ ) atoms in plasmas (see below).

\subsection{Challenges When Using ns-and ps/fs-TALIF in Plasmas}

The onset of ASE, PIN and photolytic effects when performing TALIF studies in plasmas has been also reported in different studies. Amorim et al. [49] probed by means of ns-TALIF the production of $\mathrm{O}$ and $\mathrm{H}$ atoms in $\mathrm{O}_{2}$ and $\mathrm{H}_{2}$ glow discharges. For the determination of the absolute densities of $\mathrm{O}$ and $\mathrm{H}$ atoms, absolute calibration of the TALIF signals was performed using VUV absorption spectroscopy. ASE was observed along the laser beam, and recorded simultaneously with the TALIF signal. The experimental results were coupled with a 0D numerical model capable of simulating two-photon absorption, fluorescence, PIN (through the absorption of a third photon), ASE, and collisional quenching processes. This model was the first to clearly include ASE in a TALIF scheme. The evolution of the experimentally measured O-atom TALIF and ASE signal intensities as a function of the laser pulse was also studied in [49]. For laser energies lower than $600 \mu \mathrm{J}$, no saturation of the O-TALIF signal was observed since a slope of 2 characterized the two-photon excitation process. However, above $600 \mu \mathrm{J}$, a saturation effect was observed 
both for the TALIF and ASE signal intensities. More specifically, the ASE intensity variation versus the laser energy exhibited three stages: (1) at low laser energies (up to $300 \mu \mathrm{J}$ ), the ASE intensity was below threshold thus not affecting the TALIF signal, (2) with increasing laser energy up to $600 \mu \mathrm{J}$, an exponential increase in the ASE intensity was measured, and (3) above $600 \mu \mathrm{J}$, the ASE signal was saturated. Besides, at the high laser energy range, PIN also contributed to the depopulation of the laser-excited state and, thus, to the saturation of the TALIF and ASE signal intensities. The experimental results were reproduced with the numerical model, showing a good qualitative agreement. Concerning other ns-TALIF studies, different groups used the quadratic-regime criterion to determine conditions (in terms of laser power density), for which saturation effects become significant, and thus carefully avoid them $[64,65,69,72,78,80,81,85,99,100,110,111]$. However, most of the published works do not focus on the detailed study of the processes leading to the saturation regimes, i.e., ASE and PIN. This is reasonable since the main goal of those works is the determination/manipulation of the absolute densities of reactive atomic species, and the understanding of their dynamics in the plasmas studied. This has also been the case for some recent ps- and fs-TALIF investigations focusing on the measurement of $\mathrm{O}-$ and $\mathrm{H}$-atom densities in non-equilibrium plasmas [44,45,90,91].

The limitations of ns-TALIF versus fs-TALIF on the accurate measurement of O-atom absolute density in an atmospheric pressure $\mathrm{He} / \mathrm{O}_{2}$ plasma jet was demonstrated in [90]. The use of fs-TALIF offered several advantages: (1) stronger TALIF signal intensities (normalized to the incident laser intensity), (2) more accurate determination of $\mathrm{O}\left(3 \mathrm{p}^{3} \mathrm{P}\right)$ atoms decay times and quenching rates, (3) much lower laser-induced ionization and molecular dissociation due to lower average laser-pulse power, and (4) performance of detailed two-dimensional density profiles. The main constraints of ns-TALIF and the corresponding advantage of fs-TALIF when performing sub-ns measurements of the $\mathrm{O}\left(3 \mathrm{p}^{3} \mathrm{P}\right)$ atom effective lifetime in their plasma jet were well demonstrated. In fact, the decay time of the ns-TALIF signal was similar to the ns-laser-pulse width, making the extraction of the effective lifetime very challenging. However, this was not happened when using fs-TALIF, for which the fs-laser-pulse width was much shorter than the decay time of the corresponding TALIF signal. On the other hand, Dumitrache et al. [62] used fs-TALIF and strongly focused laser beams to measure the absolute density of $\mathrm{N}$ atoms in a $\mathrm{N}_{2}$ nanosecond repetitive pulse discharge (pressure range: $0.1-5$ bar). For calibration purposes, fs-TALIF in Kr was applied. The TALIF signal intensity versus the laser intensity was plotted for both $\mathrm{N}$ and $\mathrm{Kr}$ atoms, revealing slopes of 0.95 and 0.98 , respectively. Thus, a departure from the quadratic regime was observed. This result suggested that processes other than the fluorescence and collisional quenching led to a significant depletion of the laser-excited states. According to the authors, this depletion was due to PIN and possibly ASE effects. The beam waist of the laser in their case was only of $52 \mu \mathrm{m}$, which for a $100-f s$ laser pulse, resulted to instantaneous laser peak intensities of $\sim 4 \mathrm{TW} \cdot \mathrm{cm}^{-2}$, i.e., much higher than those required to achieve photoionization. Therefore, to perform reliable density measurements of $\mathrm{N}$ atoms at elevated pressures, the processes of PIN and ASE need to be considered and avoided. Furthermore, as it was recently shown in [55], at instantaneous laser intensities higher than $1 \mathrm{GW} \cdot \mathrm{cm}^{-2}$, photoionization becomes the main loss mechanism of laser-excited $\mathrm{O}$ atoms and the saturation regime is rapidly reached. In this case, the dynamics of the system is accurately described using density-matrix equations instead of rate equation models (see [55] for more details).

\section{Conclusions}

The present review was focused on the advances of fast (ns) and ultrafast (ps and fs) TALIF diagnostics for probing reactive atoms in plasmas and flames. When used properly, these diagnostics allow for the precise determination of atomic densities in different reactive media, leading to a better understanding of various physicochemical processes involved. At first, the basic features characterizing the various lasers used in TALIF diagnostics were given. Then, the key principles and theory of TALIF, the 
properties of the investigated reactive (particularly $\mathrm{N}, \mathrm{H}$ and $\mathrm{O}$ ) and calibrating $(\mathrm{Kr}$ and $\mathrm{Xe})$ atomic species, the different calibration procedures, and the requirements for the correct application of TALIF were listed based on representative published studies. Similarly, the effective implementation of fast and ultrafast TALIF for evaluating species densities, radiative lifetimes, and quenching coefficients in plasmas and flames was demonstrated. Finally, the main challenges encountered while using ns- and ps/fs-TALIF as well as methods to avoid them were discussed.

In summary, most of the published studies up to date concern ns-TALIF, which is in general consistent for measurements performed in relatively large timescales (tens of ns- $\mu \mathrm{s}-$ $\mathrm{ms}$, i.e., larger than the pulse duration of ns lasers), and gas pressures lower than $10 \mathrm{mbar}$. This is because the collisional quenching of laser-excited states becomes significant with increasing pressure depending on the species and the quencher nature. Thus, in this case, the use of ps and fs lasers is more advantageous in resolving the TALIF decay since they offer much shorter pulse widths, higher instantaneous laser intensities, and similar average powers compared to ns lasers. Furthermore, special attention needs to be paid in order to ensure the quadratic dependence between the TALIF signal intensity and the laser pulse energy. This requires very low instantaneous laser intensities, which can be achieved by using unfocused laser beams or laser sheets, especially when applying ps/fs-TALIF. At higher laser intensities (i.e., outside of the quadratic regime of excitation), a saturation of the TALIF signal has been observed in different studies (both for ns- and ps/fs-TALIF) due to photodissociation, and/or photoionization (PIN), and/or amplified stimulated emission (ASE). PIN and ASE lead to the rapid depletion of the laser-excited states, limiting the fluorescence yield and, thus, the TALIF signal intensity. On the other hand, photodissociation leads to the production of excessive atoms from precursor molecules, which will alter the atom density measurement.

Finally, compared to the species single-photon absorption cross-sections required in LIF, the two-photon absorption cross-sections $\left(\sigma^{(2)}\right)$ in TALIF are much lower. This makes difficult the accurate determination of $\sigma^{(2)}$, which is required for extracting absolute densities from TALIF measurements. Particularly, the values of $\sigma^{(2)}$ for $\mathrm{Kr}$ and Xe atoms, which are necessary to calibrate absolute density measurements of $\mathrm{H}, \mathrm{N}$, and $\mathrm{O}$ atoms, are not available. To overcome this issue, most of the published studies use the ratios of $\sigma^{(2)}$ between those calibrating species and the reactive species of interest $(\mathrm{H}, \mathrm{N}, \mathrm{O})$, as determined by titration methods in $[40,76,90]$. However, these values were determined with $20 \%$ (ratio: $\mathrm{Xe} / \mathrm{O}$ ) and $50 \%$ (ratios: $\mathrm{Kr} / \mathrm{H}$ and $\mathrm{Kr} / \mathrm{N}$ ) uncertainties. This is a limiting factor on the more accurate absolute density measurement of reactive atoms (particularly $\mathrm{H}$ and $\mathrm{N}$ atoms) in plasmas and flames. Therefore, a more precise determination of those cross-section ratios should be considered in the future.

Author Contributions: K.G. conceived and wrote the first draft of the manuscript. All authors contributed equally by reading it and making pertinent suggestions, which led to the final submitted version. All authors have read and agreed to the published version of the manuscript.

Funding: The present work was supported by the French 'Agence Nationale de la Recherche' (ANR) through the ASPEN project (grant ANR-16-CE30-0004/ASPEN), and by the SESAME research and innovation programme of the Ile-de-France Region under the project grant DIAGPLAS.

Institutional Review Board Statement: Not applicable.

Informed Consent Statement: Not applicable.

Data Availability Statement: The data presented in this study are available on request from the corresponding author.

Conflicts of Interest: The authors declare no conflict of interest. The founding sponsors had no role in the design of the study; in the collection, analyses, or interpretation of data; in the writing of the manuscript, and in the decision to publish the results. 


\section{References}

1. Bertolotti, M. The History of the Laser; CRC Press: Boca Raton, FL, USA, 2005. [CrossRef]

2. Gamaly, E.G.; Rode, A.V. Physics of ultra-short laser interaction with matter: From phonon excitation to ultimate transformations. Prog. Quantum Electron. 2013, 37, 215-323. [CrossRef]

3. Demtröder, W. Laser Spectroscopy Vol. 1: Basic Principles; Springer: Berlin/Heidelberg, Germany, 2008. [CrossRef]

4. Wetzig, A.; Herwig, P.; Hauptmann, J.; Baumann, R.; Rauscher, P.; Schlosser, M.; Pinder, T.; Leyens, C. Fast laser cutting of thin metal. Procedia Manuf. 2019, 29, 369-374. [CrossRef]

5. Bachmann, M.; Gumenyuk, A.; Rethmeier, M. Welding with high-power lasers: Trends and developments. Phys. Procedia 2016, 83, 15-25. [CrossRef]

6. Ceccarelli, F.; Atzeni, S.; Pentangelo, C.; Pellegatta, F.; Crespi, A.; Osellame, R. Low power reconfigurability and reduced crosstalk in integrated photonic circuits fabricated by femtosecond laser micromachining. Laser Photonics Rev. 2020, 14, 1-10. [CrossRef]

7. Luke, A.M.; Mathew, S.; Altawash, M.M.; Madan, B.M. Lasers: A review with their applications in oral medicine. J. Lasers Med. Sci. 2019, 10, 324-329. [CrossRef] [PubMed]

8. Khalkhal, E.; Rezaei-Tavirani, M.; Zali, M.R.; Akbari, Z. The evaluation of laser application in surgery: A review article. J. Lasers Med. Sci. 2019, 10, S104-S111. [CrossRef] [PubMed]

9. Jipa, F.; Zamfirescu, M.; Velea, A.; Popescu, M.; Dabu, R. Updates in Advanced Lithography (Chapter 3: Femtosecond Laser Lithography in Organic and Non-Organic Materials); IntechOpen: Rijeka, Croatia, 2013; ISBN 978-953-51-5709-0. [CrossRef]

10. Gazeli, O.; Bellou, E.; Stefas, D.; Couris, S. Laser-based classification of olive oils assisted by machine learning. Food Chem. 2020, 302, 125329. [CrossRef]

11. Lefort, C. A review of biomedical multiphoton microscopy and its laser sources. J. Phys. D Appl. Phys. 2017, 50, 423001. [CrossRef]

12. Hübner, S.; Sousa, J.S.; van der Mullen, J.; Graham, W.G. Thomson scattering on non-thermal atmospheric pressure plasma jets. Plasma Sources Sci. Technol. 2015, 24, 054005. [CrossRef]

13. Verreycken, T.; van Gessel, A.F.H.; Pageau, A.; Bruggeman, P. Validation of gas temperature measurements by OES in an atmospheric air glow discharge with water electrode using Rayleigh scattering. Plasma Sources Sci. Technol. 2011, $20,024002$. [CrossRef]

14. Gazeli, K.; Bauville, G.; Fleury, M.; Jeanney, P.; Neveu, O.; Pasquiers, S.; Santos Sousa, J. Effect of the gas flow rate on the spatiotemporal distribution of $\operatorname{Ar}\left(1 s_{5}\right)$ absolute densities in a ns pulsed plasma jet impinging on a glass surface. Plasma Sources Sci. Technol. 2018, 27, 065003. [CrossRef]

15. Gazeli, K.; Vazquez, T.; Al-Homsi, S.; Bauville, G.; Blin-Simiand, N.; Bournonville, B.; Fleury, M.; Jeanney, P.; Neveu, O.; Pasquiers, S.; et al. Ar $\left(1 \mathrm{~s}_{5}\right)$ absolute radial densities in a ns-pulsed argon plasma jet impinging on dielectric targets at floating potential-plasma action on organic molecules. Plasma Process. Polym. 2018, 15, e1800080. [CrossRef]

16. Gazeli, K.; Vazquez, T.; Bauville, G.; Blin-Simiand, N.; Bournonville, B.; Pasquiers, S.; Santos Sousa, J. Experimental investigation of a ns-pulsed argon plasma jet for the fast desorption of weakly volatile organic compounds deposited on glass substrates at variable electric potential. J. Phys. D Appl. Phys. 2020, 53, 475202. [CrossRef]

17. Darny, T.; Pouvesle, J.; Puech, V.; Douat, C.; Dozias, S.; Robert, E. Analysis of conductive target influence in plasma jet experiments through helium metastable and electric field measurements. Plasma Sources Sci. Technol. 2017, 26, 045008. [CrossRef]

18. Chng, T.L.; Orel, I.; Adamovich, I.V.; Popov, N.A.; Starikovskaia, S. N-atom production at high electric fields: E-FISH and TALIF experiments for understanding fast ionization wave kinetics. AIAA Scitech Forum 2020. [CrossRef]

19. Chng, T.L.; Brisset, A.; Jeanney, P.; Starikovskaia, S.M.; Adamovich, I.V.; Tardiveau, P. Electric field evolution in a diffuse ionization wave nanosecond pulse discharge in atmospheric pressure air. Plasma Sources Sci. Technol. 2019, 28, 09LT02. [CrossRef]

20. Goldberg, B.M.; Reuter, S.; Dogariu, A.; Miles, R.B. 1-D spatially resolved electric fields in atmospheric pressure nanosecond pulse discharges using ultrashort laser pulses. AIAA Scitech Forum 2019. [CrossRef]

21. Dogariu, L.E.; Dogariu, A.; Miles, R.B.; Smith, M.S.; Marineau, E.C. Femtosecond laser electronic excitation tagging velocimetry in a large-scale hypersonic facility. AIAAJ 2019, 57, 4725-4737. [CrossRef]

22. Moreau, E.; Audier, P.; Orriere, T.; Benard, N. Electrohydrodynamic gas flow in a positive corona discharge. J. Appl. Phys. 2019, 125, 133303. [CrossRef]

23. Stancu, G.D.; Kaddouri, F.; Lacoste, D.A.; Laux, C.O. Atmospheric pressure plasma diagnostics by OES, CRDS and TALIF. J. Phys. D Appl. Phys. 2010, 43, 124002. [CrossRef]

24. Patnaik, A.K.; Adamovich, I.; Gord, J.R.; Roy, S. Recent advances in ultrafast-laser-based spectroscopy and imaging for reacting plasmas and flames. Plasma Sources Sci. Technol. 2017, 26, 103001. [CrossRef]

25. Dilecce, G.; Martini, L.M.; Tosi, P.; Scotoni, M.; De Benedictis, S. Laser induced fluorescence in atmospheric pressure discharges. Plasma Sources Sci. Technol. 2015, 24, 034007. [CrossRef]

26. Tango, W.J.; Link, J.K.; Zare, R.N. Spectroscopy of $\mathrm{K}_{2}$ using laser-induced fluorescence. J. Chem. Phys. 1968, $49,4264-4268$. [CrossRef]

27. Bruggeman, P.; Brandenburg, R. Atmospheric pressure discharge filaments and microplasmas: Physics, chemistry and diagnostics. J. Phys. D Appl. Phys. 2013, 46, 464001. [CrossRef]

28. Amorim, J.; Baravian, G.; Jolly, J. Laser-induced resonance fluorescence as a diagnostic technique in non-thermal equilibrium plasmas. J. Phys. D Appl. Phys. 2000, 33, R51-R65. [CrossRef] 
29. Döbele, H.F.; Mosbach, T.; Niemi, K.; Schulz-von der Gathen, V. Laser-induced fluorescence measurements of absolute atomic densities: Concepts and limitations. Plasma Sources Sci. Technol. 2005, 14, S31-S41. [CrossRef]

30. Telle, H.H.; Urena, A.G.; Donovan, R.J. Laser Chemistry: Spectroscopy, Dynamics and Applications; John Wiley \& Sons Ltd.: West Sussex, UK, 2007; ISBN 978-0-471-48570-4 (HB).

31. Herzberg, G. Molecular Spectra and Molecular Structure I; Spectra of Diatomic Molecules; D. Van Nostrand Company, INC.: Princeton, NJ, USA, 1950.

32. Ouaras, K.; Magne, L.; Pasquiers, S.; Tardiveau, P.; Jeanney, P.; Bournonville, B. OH density measured by PLIF in a nanosecond atmospheric pressure diffuse discharge in humid air under steep high voltage pulses. Plasma Sources Sci. Technol. 2018, $27,045002$. [CrossRef]

33. Bokor, J.; Freeman, R.R.; White, J.C.; Storz, R.H. Two-photon excitation of the $\mathrm{n}=3$ level in H and D atoms. Phys. Rev. A 1981, 24, 612-614. [CrossRef]

34. Bischel, W.K.; Perry, B.E.; Crosley, D.R. Two-photon laser-induced fluorescence in oxygen and nitrogen atoms. Chem. Phys. Lett. 1981, 82, 85-88. [CrossRef]

35. Bischel, W.K.; Perry, B.E.; Crosley, D.R. Detection of fluorescence from O and N atoms induced by two-photon absorption. Appl. Opt. 1982, 21, 1419. [CrossRef] [PubMed]

36. Niemi, K.; Schulz-von der Gathen, V.; Döbele, H.F. Absolute calibration of atomic density measurements by laser-induced fluorescence spectroscopy with two-photon excitation. J. Phys. D Appl. Phys. 2001, 34, 2330-2335. [CrossRef]

37. Aldén, M.; Edner, H.; Grafström, P.; Svanberg, S. Two-photon excitation of atomic oxygen in a flame. Opt. Commun. 1982, 42, 244-246. [CrossRef]

38. Goldsmith, J.E.M. Two-photon-excited stimulated emission from atomic hydrogen in flames. J. Opt. Soc. Am. B 1989, 6, 1979. [CrossRef]

39. Agrup, S.; Westblom, U.; Aldén, M. Detection of atomic nitrogen using two-photon laser-induced stimulated emission: Application to flames. Chem. Phys. Lett. 1990, 170, 406-410. [CrossRef]

40. Es-sebbar, E.T.; C-Gazeau, M.; Benilan, Y.; Jolly, A.; Pintassilgo, C.D. Absolute ground-state nitrogen atom density in a $\mathrm{N}_{2} / \mathrm{CH}_{4}$ late afterglow: TALIF experiments and modelling studies. J. Phys. D Appl. Phys. 2010, 43, 335203. [CrossRef]

41. Duan, X.R.; Lange, H.; Meyer-Plath, A. Absolute density distribution of $\mathrm{H}$ atoms in a large-scale microwave plasma reactor. Plasma Sources Sci. Technol. 2003, 12, 554-560. [CrossRef]

42. Yue, Y.; Kondeti, V.S.S.K.; Bruggeman, P.J. Absolute atomic hydrogen density measurements in an atmospheric pressure plasma jet: Generation, transport and recombination from the active discharge region to the effluent. Plasma Sources Sci. Technol. 2020, 29, 04LT01. [CrossRef]

43. Dumitrache, C.; Gallant, A.; Stancu, G.D.; Laux, C.O. Ground-state atomic nitrogen measurements using fs-TALIF in high-pressure NRP discharges. AIAA Scitech Forum 2020. [CrossRef]

44. Schröter, S.; Bredin, J.; Gibson, A.R.; West, A.; Dedrick, J.P.; Wagenaars, E.; Niemi, K.; Gans, T.; O'Connell, D. The formation of atomic oxygen and hydrogen in atmospheric pressure plasmas containing humidity: Picosecond two-photon absorption laser induced fluorescence and numerical simulations. Plasma Sources Sci. Technol. 2020, 29, 105001. [CrossRef]

45. Schmidt, J.B.; Sands, B.L.; Kulatilaka, W.D.; Roy, S.; Scofield, J.; Gord, J.R. Femtosecond, two-photon laser-induced-fluorescence imaging of atomic oxygen in an atmospheric-pressure plasma jet. Plasma Sources Sci. Technol. 2015, 24, 032004. [CrossRef]

46. Westblom, U.; Agrup, S.; Aldén, M.; Cederbalk, P. Detection of nitrogen atoms in flames using two-photon laser-induced fluorescence and investigations of photochemical effects. Appl. Opt. 1991, 30, 2990. [CrossRef] [PubMed]

47. Agrup, S.; Aldén, M. Two-photon laser-induced fluorescence and stimulated emission measurements from oxygen atoms in a hydrogen/oxygen flame with picosecond resolution. Opt. Commun. 1994, 113, 315-323. [CrossRef]

48. Agrup, S.; Ossler, F.; Aldén, M. Measurements of collisional quenching of hydrogen atoms in an atmospheric-pressure hydrogen oxygen flame by picosecond laser-induced fluorescence. Appl. Phys. B Lasers Opt. 1995, 61, 479-487. [CrossRef]

49. Amorim, J.; Baravian, G.; Touzeau, M.; Jolly, J. Two-photon laser induced fluorescence and amplified spontaneous emission atom concentration measurements in $\mathrm{O}_{2}$ and $\mathrm{H}_{2}$ discharges. J. Appl. Phys. 1994, 76, 1487-1493. [CrossRef]

50. Lukas, C.; Spaan, M.; Der Gathen, V.S.-V.; Thomson, M.; Wegst, R.; Döbele, H.F.; Neiger, M. Dielectric barrier discharges with steep voltage rise: Mapping of atomic nitrogen in single filaments measured by laser-induced fluorescence spectroscopy. Plasma Sources Sci. Technol. 2001, 10, 445-450. [CrossRef]

51. Frank, J.H.; Settersten, T.B. Two-photon LIF imaging of atomic oxygen in flames with picosecond excitation. Proc. Combust. Inst. 2005, 30, 1527-1534. [CrossRef]

52. Frank, J.H.; Chen, X.; Patterson, B.D.; Settersten, T.B. Comparison of nanosecond and picosecond excitation for interference-free two-photon laser-induced fluorescence imaging of atomic oxygen in flames. Appl. Opt. 2004, 43, 2588. [CrossRef]

53. Kulatilaka, W.D.; Frank, J.H.; Settersten, T.B. Interference-free two-photon LIF imaging of atomic hydrogen in flames using picosecond excitation. Proc. Combust. Inst. 2009, 32, 955-962. [CrossRef]

54. Kulatilaka, W.D.; Gord, J.R.; Katta, V.R.; Roy, S. Photolytic-interference-free, femtosecond two-photon fluorescence imaging of atomic hydrogen. Opt. Lett. 2012, 37, 3051. [CrossRef]

55. Stancu, G.D. Two-photon absorption laser induced fluorescence: Rate and density-matrix regimes for plasma diagnostics. Plasma Sources Sci. Technol. 2020, 29, 054001. [CrossRef]

56. Loudon, R. The Quantum Theory of Light; Clarendon: Oxford, UK, 1983. 
57. Masalov, A.V. Spectral and temporal fluctuations of broadband laser radiation. Prog. Opt. 1985, 22, 145-196.

58. Payne, M.G.; Chen, C.H.; Hurst, G.S.; Foltz, G.W. Applications of resonance ionization spectroscopy in atomic and molecular physics. Adv. At. Mol. Opt. 1982, 17, 229-274.

59. Bamford, D.J.; Jusinski, L.E.; Bischel, W.K. Absolute two-photon absorption and three-photon ionization cross sections for atomic oxygen. Phys. Rev. A 1986, 34, 185-198. [CrossRef] [PubMed]

60. Kroll, S.; Aldén, M.; Bengtsson, P.-E.; Lofström, C.; Hall, R.J. Statistics of multimode YAG laser radiation with implications for quantitative coherent anti-Stokes Raman scattering spectroscopy in combustion diagnostics. J. Opt. Soc. Am. B 1991, 8, 5. [CrossRef]

61. Van Gessel, A.F.H.; Van Grootel, S.C.; Bruggeman, P.J. Atomic oxygen TALIF measurements in an atmospheric-pressure microwave plasma jet with in situ xenon calibration. Plasma Sources Sci. Technol. 2013, 22, 055010. [CrossRef]

62. Dumitrache, C.; Gallant, A.; Stancu, G.D.; Laux, C.O. Femtosecond two-photon absorption laser induced fluorescence (fs-TALIF) imaging of atomic nitrogen in nanosecond repetitive discharges. AIAA Scitech Forum 2019. [CrossRef]

63. Tserepi, A.D.; Dunlop, J.R.; Preppernau, B.L.; Miller, T.A. Absolute H-atom concentration profiles in continuous and pulsed rf discharges. J. Appl. Phys. 1992, 72, 2638-2643. [CrossRef]

64. Mrkvičková, M.; Ráhel', J.; Dvořák, P.; Trunec, D.; Morávek, T. Fluorescence (TALIF) measurement of atomic hydrogen concentration in a coplanar surface dielectric barrier discharge. Plasma Sources Sci. Technol. 2016, 25, 055015. [CrossRef]

65. Yatom, S.; Luo, Y.; Xiong, Q.; Bruggeman, P.J. Nanosecond pulsed humid Ar plasma jet in air: Shielding, discharge characteristics and atomic hydrogen production. J. Phys. D Appl. Phys. 2017, 50, 415204. [CrossRef]

66. Adams, S.F.; Miller, T.A. Two-photon absorption laser-induced fluorescence of atomic nitrogen by an alternative excitation scheme. Chem. Phys. Lett. 1998, 295, 305-311. [CrossRef]

67. Mazouffre, S.; Bakker, I.; Vankan, P.; Engeln, R.; Schram, D.C. Two-photon laser induced fluorescence spectroscopy performed on free nitrogen plasma jets. Plasma Sources Sci. Technol. 2002, 11, 439-447. [CrossRef]

68. Wagenaars, E.; Gans, T.; O'Connell, D.; Niemi, K. Two-photon absorption laser-induced fluorescence measurements of atomic nitrogen in a radio-frequency atmospheric-pressure plasma jet. Plasma Sources Sci. Technol. 2012, 21, 042002. [CrossRef]

69. Ono, R.; Teramoto, Y.; Oda, T. Measurement of atomic nitrogen in $\mathrm{N}_{2}$ pulsed positive corona discharge using two-photon absorption laser-induced fluorescence. Jpn. J. Appl. Phys. 2009, 48, 122302. [CrossRef]

70. Es-Sebbar, E.T.; Gherardi, N.; Massines, F. Effects of $\mathrm{N}_{2} \mathrm{O}$ and $\mathrm{O}_{2}$ addition to nitrogen Townsend dielectric barrier discharges at atmospheric pressure on the absolute ground-state atomic nitrogen density. J. Phys. D Appl. Phys. 2013, 46, 015202. [CrossRef]

71. Dvořák, P.; Šimek, M.; Prukner, V. Evolution of $\mathrm{N}\left({ }^{4} \mathrm{~S}\right)$ atoms produced under nitrogen streamer conditions: Time-resolved TALIF study at reduced pressures. Plasma Sources Sci. Technol. 2019, 28, 125004. [CrossRef]

72. Chng, T.L.; Lepikhin, N.D.; Orel, I.S.; Popov, N.A.; Starikovskaia, S.M. TALIF measurements of atomic nitrogen in the afterglow of a nanosecond capillary discharge. Plasma Sources Sci. Technol. 2020, 29, 035017. [CrossRef]

73. Goldsmith, J.E.M. Photochemical effects in two-photon-excited fluorescence detection of atomic oxygen in flames. Appl. Opt. 1987, 26, 3566. [CrossRef] [PubMed]

74. Wysong, I.J.; Jeffries, J.B.; Crosley, D.R. Laser-induced fluorescence of $\mathrm{O}\left(3 p^{3} P\right), \mathrm{O}_{2}$, and NO near 226 nm: Photolytic interferences and simultaneous excitation in flames. Opt. Lett. 1989, 14, 767-769. [CrossRef] [PubMed]

75. Van Oostendorp, D.L.; Levinsky, H.B.; van der Meij, C.E.; Jacobs, R.A.A.M.; Borghols, W.T.A. Avoidance of the photochemical production of oxygen atoms in one-dimensional, two-photon laser-induced fluorescence imaging. Appl. Opt. 1993, 32, 4636. [CrossRef] [PubMed]

76. Tserepi, A.D.; Wurzberg, E.; Miller, T.A. Two-photon-excited stimulated emission from atomic oxygen in rf plasmas: Detection and estimation of its threshold. Chem. Phys. Lett. 1997, 265, 297-302. [CrossRef]

77. Dilecce, G.; Vigliotti, M.; De Benedictis, S. A TALIF calibration method for quantitative oxygen atom density measurement in plasma jets. J. Phys. D Appl. Phys. 2000, 33, L53-L56. [CrossRef]

78. Niemi, K.; Schulz-von der Gathen, V.; Döbele, H.F. Absolute atomic oxygen density measurements by two-photon absorption laser-induced fluorescence spectroscopy in an RF-excited atmospheric pressure plasma jet. Plasma Sources Sci. Technol. 2005, 14, 375-386. [CrossRef]

79. Waskoenig, J.; Niemi, K.; Knake, N.; Graham, L.M.; Reuter, S.; Schulz-von der Gathen, V.; Gans, T. Atomic oxygen formation in a radio-frequency driven micro-atmospheric pressure plasma jet. Plasma Sources Sci. Technol. 2010, 19, 045018. [CrossRef]

80. Reuter, S.; Winter, J.; Schmidt-Bleker, A.; Schroeder, D.; Lange, H.; Knake, N.; Schulz-von der Gathen, V.; Weltmann, K.-D. Atomic oxygen in a cold argon plasma jet: TALIF spectroscopy in ambient air with modelling and measurements of ambient species diffusion. Plasma Sources Sci. Technol. 2012, 21, 024005. [CrossRef]

81. Jia, F.; Ishikawa, K.; Takeda, K.; Kano, H.; Kularatne, J.; Kondo, H.; Sekine, M.; Hori, M. Spatiotemporal behaviors of absolute density of atomic oxygen in a planar type of $\mathrm{Ar} / \mathrm{O}_{2}$ non-equilibrium atmospheric-pressure plasma jet. Plasma Sources Sci. Technol. 2014, 23, 025004. [CrossRef]

82. Klochko, A.V.; Lemainque, J.; Booth, J.P.; Starikovskaia, S.M. TALIF measurements of oxygen atom density in the afterglow of a capillary nanosecond discharge. Plasma Sources Sci. Technol. 2015, 24, 025010. [CrossRef]

83. Marinov, D.; Drag, C.; Blondel, C.; Guaitella, O.; Golda, J.; Klarenaar, B.; Engeln, R.; Schulz-von der Gathen, V.; Booth, J.P. Pressure broadening of atomic oxygen two-photon absorption laser induced fluorescence. Plasma Sources Sci. Technol. 2016, 25, 06LT03. [CrossRef] 
84. Li, D.; Kong, M.G.; Britun, N.; Snyders, R.; Leys, C.; Nikiforov, A. Quantitative measurements of ground state atomic oxygen in atmospheric pressure surface micro-discharge array. J. Phys. D Appl. Phys. 2017, 50, 215201. [CrossRef]

85. Nakagawa, Y.; Kawakita, T.; Uchida, S.; Tochikubo, F. Simultaneous measurement of local densities of atomic oxygen and ozone in pure oxygen pulsed barrier discharge under atmospheric pressure. J. Phys. D Appl. Phys. 2020, 53, 135201. [CrossRef]

86. Meler, U.; Kohse-Höinghaus, K.; Just, T. H and O atom detection for combustion applications: Study of quenching and laser photolysis effects. Chem. Phys. Lett. 1986, 126, 567-573. [CrossRef]

87. Broc, A.; De Benedictis, S.; Dilecce, G. LIF investigations on $\mathrm{NO}, \mathrm{O}$ and $\mathrm{N}$ in a supersonic $\mathrm{N}_{2} / \mathrm{O}_{2} / \mathrm{NO}_{\mathrm{RF}}$ plasma jet. Plasma Sources Sci. Technol. 2004, 13, 504-514. [CrossRef]

88. Kulatilaka, W.D.; Patterson, B.D.; Frank, J.H.; Settersten, T.B. Comparison of nanosecond and picosecond excitation for interference-free two-photon laser-induced fluorescence detection of atomic hydrogen in flames. Appl. Opt. 2008, 47, 4672. [CrossRef] [PubMed]

89. Settersten, T.B.; Dreizler, A.; Patterson, B.D.; Schrader, P.E.; Farrow, R.L. Photolytic interference affecting two-photon laser-induced fluorescence detection of atomic oxygen in hydrocarbon flames. Appl. Phys. B Lasers Opt. 2003, 76, 479-482. [CrossRef]

90. Schmidt, J.B.; Sands, B.; Scofield, J.; Gord, J.R.; Roy, S. Comparison of femtosecond- and nanosecond-two-photon-absorption laser-induced fluorescence (TALIF) of atomic oxygen in atmospheric-pressure plasmas. Plasma Sources Sci. Technol. 2017, 26, 055004. [CrossRef]

91. Schmidt, J.B.; Roy, S.; Kulatilaka, W.D.; Shkurenkov, I.; Adamovich, I.V.; Lempert, W.R.; Gord, J.R. Femtosecond, two-photonabsorption, laser-induced-fluorescence (fs-TALIF) imaging of atomic hydrogen and oxygen in non-equilibrium plasmas. J. Phys. D Appl. Phys. 2017, 50, 015204. [CrossRef]

92. Goehlich, A.; Kawetzki, T.; Döbele, H.F. On absolute calibration with xenon of laser diagnostic methods based on two-photon absorption. J. Chem. Phys. 1998, 108, 9362-9370. [CrossRef]

93. Saxon, R.P.; Eichler, J. Theoretical calculation of two-photon absorption cross sections in atomic oxygen. Phys. Rev. A 1986, 34, 199-206. [CrossRef] [PubMed]

94. Gontier, Y.; Trahin, M. On the multiphoton absorption in atomic hydrogen. Phys. Lett. A 1971, 36, 463-464. [CrossRef]

95. Tung, J.H.; Tang, A.Z.; Salamo, G.J.; Chan, F.T. Two-photon absorption of atomic hydrogen from two light beams. J. Opt. Soc. Am. $B$ 1986, 3, 837. [CrossRef]

96. Gontier, Y.; Trahin, M. Multiphoton processes in a hydrogen atom. Phys. Rev. A 1971, 4, 1896-1906. [CrossRef]

97. Gazeli, K.; Aubert, X.; Swaminathan, P.; Duluard, C.Y.; Lombardi, G.; Hassouni, K. Picosecond two-photon laser induced fluorescence (ps-TALIF) in krypton: Preventing saturation regimes for reliable calibration of atomic densities. Phys. Plasmas 2020. Submitted on 23 December 2020. Available online: https:/ / hal.archives-ouvertes.fr/hal-03087285v1 (accessed on 29 December 2020).

98. Miyazaki, K.; Kajiwara, T.; Uchino, K.; Muraoka, K.; Okada, T.; Maeda, M. Laser-induced dissociation of molecules during measurements of hydrogen atoms in processing plasmas using two-photon laser-induced fluorescence. J. Vac. Sci. Technol. A 1996, 14, 125-131. [CrossRef]

99. Reuter, S.; Niemi, K.; Schulz-von der Gathen, V.; Döbele, H.F. Generation of atomic oxygen in the effluent of an atmospheric pressure plasma jet. Plasma Sources Sci. Technol. 2009, 18, 015006. [CrossRef]

100. Es-Sebbar, E.-T.; Sarra-Bournet, C.; Naudé, N.; Massines, F.; Gherardi, N. Absolute nitrogen atom density measurements by two-photon laser-induced fluorescence spectroscopy in atmospheric pressure dielectric barrier discharges of pure nitrogen. $J$. Appl. Phys. 2009, 106, 073302. [CrossRef]

101. Teramoto, Y.; Ono, R.; Oda, T. Production mechanism of atomic nitrogen in atmospheric pressure pulsed corona discharge measured using two-photon absorption laser-induced fluorescence. J. Appl. Phys. 2012, 111, 113302. [CrossRef]

102. Zhang, S.; van Gessel, A.F.H.; van Grootel, S.C.; Bruggeman, P.J. The effect of collisional quenching of the O3p $\mathrm{p}^{3} \mathrm{P}_{J}$ state on the determination of the spatial distribution of the atomic oxygen density in an APPJ operating in ambient air by TALIF. Plasma Sources Sci. Technol. 2014, 23, 025012. [CrossRef]

103. Bergano, N.S.; Bechtel, J.H.; Jaanimagi, P.A.; Salour, M.M. Picosecond laser-spectroscopy measurement of hydroxyl fluorescence lifetime in flames. Opt. Lett. 1983, 8, 443. [CrossRef] [PubMed]

104. Wang, Y.; Capps, C.; Kulatilaka, W.D. Femtosecond two-photon laser-induced fluorescence of krypton for high-speed flow imaging. Opt. Lett. 2017, 42, 711. [CrossRef] [PubMed]

105. West, A.; Bredin, J.; Schröter, S.; Niemi, K.; Dedrick, J.; O'Connell, D.; Gans, T.; Wagenaars, E. Picosecond two-photon absorption laser induced fluorescence for measuring reactive atomic species in atmospheric-prtessure plasma jets. In Proceedings of the 19th International Conference on Atomic Processes in Plasmas (APiP), Paris, France, 4-8 April 2016.

106. Conway, J.; Gogna, G.S.; Gaman, C.; Turner, M.M.; Daniels, S. Two-photon absorption laser induced fluorescence measurement of atomic oxygen density in an atmospheric pressure air plasma jet. Plasma Sources Sci. Technol. 2016, 25, 045023. [CrossRef]

107. Brisset, A.; Gazeli, K.; Magne, L.; Pasquiers, S.; Jeanney, P.; Marode, E.; Tardiveau, P. Modification of the electric field distribution in a diffuse streamer-induced discharge under extreme overvoltage. Plasma Sources Sci. Technol. 2019, 28, 055016. [CrossRef]

108. Goldsmith, J.E.M.; Aldén, M.; Westblom, U. Two-photon-excited stimulated emission from atomic oxygen in flames and cold gases. Opt. Lett. 1989, 14, 305.

109. Alekseev, V.; Setser, D.W. Quenching rate constants and product assignments for reactions of $\mathrm{Xe}\left(7 \mathrm{p}[3 / 2]_{2}, 7 \mathrm{p}[5 / 2]_{2}\right.$, and $\left.6 \mathrm{p}^{\prime}[3 / 2]_{2}\right)$ atoms with rare gases, $\mathrm{CO}, \mathrm{H}_{2}, \mathrm{~N}_{2} \mathrm{O}, \mathrm{CH}_{4}$, and halogen-containing molecules. J. Phys. Chem. 1996, 100, 5766-5780. [CrossRef] 
110. Mazouffre, S.; Foissac, C.; Supiot, P.; Vankan, P.; Engeln, R.; Schram, D.C.; Sadeghi, N. Density and temperature of N atoms in the afterglow of a microwave discharge measured by a two-photon laser-induced fluorescence technique. Plasma Sources Sci. Technol. 2001, 10, 168-175. [CrossRef]

111. Gaboriau, F.; Cvelbar, U.; Mozetic, M.; Erradi, A.; Rouffet, B. Comparison of TALIF and catalytic probes for the determination of nitrogen atom density in a nitrogen plasma afterglow. J. Phys. D Appl. Phys. 2009, 42, 055204. [CrossRef] 